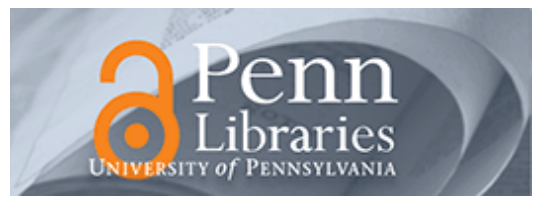

University of Pennsylvania

ScholarlyCommons

Finance Papers

Wharton Faculty Research

2002

\title{
An Empirical Analysis of Personal Bankruptcy and Delinquency
}

David B. Gross

Nicholas S. Souleles

University of Pennsylvania

Follow this and additional works at: https://repository.upenn.edu/fnce_papers

Part of the Finance Commons, and the Finance and Financial Management Commons

\section{Recommended Citation}

Gross, D. B., \& Souleles, N. S. (2002). An Empirical Analysis of Personal Bankruptcy and Delinquency.

Review of Financial Studies, 15(1), 319-347. http://dx.doi.org/10.1093/rfs/15.1.319

This paper is posted at ScholarlyCommons. https://repository.upenn.edu/fnce_papers/329

For more information, please contact repository@pobox.upenn.edu. 


\title{
An Empirical Analysis of Personal Bankruptcy and Delinquency
}

\begin{abstract}
This article uses a new dataset of credit card accounts to analyze credit card delinquency, personal bankruptcy, and the stability of credit risk models. We estimate duration models for default and assess the relative importance of different variables in predicting default. We investigate how the propensity to default has changed over time, disentangling the two leading explanations for the recent increase in default rates-a deterioration in the risk composition of borrowers versus an increase in borrowers' willingness to default due to declines in default costs. Even after controlling for risk composition and economic fundamentals, the propensity to default significantly increased between 1995 and 1997. Standard default models missed an important time-varying default factor, consistent with a decline in default costs.
\end{abstract}

Disciplines

Finance | Finance and Financial Management 
NBER WORKING PAPER SERIES

AN EMPIRICAL ANALYSIS OF PERSONAL BANKRUPTCY AND DELINQUENCY

\author{
David B. Gross \\ Nicholas S. Souleles \\ Working Paper 8409 \\ http://www.nber.org/papers/w8409 \\ NATIONAL BUREAU OF ECONOMIC RESEARCH \\ 1050 Massachusetts Avenue \\ Cambridge, MA 02138 \\ August 2001
}

We would like to thank the editor and two anonymous referees, Andy Abel, Jason Abrevaya, Franklin Allen, Larry Ausubel, Chris Carroll, Gary Gorton, Jon Gruber, Anil Kashyap, Olivia Mitchell, David Musto, Tony Santomero, Todd Sinai, Alwyn Young, and seminar participants at Columbia, the Federal Reserve Bank of Chicago, NYU, Maryland, Northwestern, the Federal Reserve Board of Governors, M.I.T., Brown, the NBER Summer Institute, and various workshops at the University of Chicago GSB and The Wharton School. We are grateful to the Wharton Financial Institutions Center and several credit card issuers for numerous discussions and assistance in acquiring the data. All remaining errors are our own. The views expressed herein are those of the authors and not necessarily those of the National Bureau of Economic Research.

(C) 2001 by David B. Gross and Nicholas S. Souleles. All rights reserved. Short sections of text, not to exceed two paragraphs, may be quoted without explicit permission provided that full credit, including $\subseteq$ notice, is given to the source. 
An Empirical Analysis of Personal Bankruptcy and Delinquency

David B. Gross and Nicholas S. Souleles

NBER Working Paper No. 8409

August 2001

JEL No. E21, E51, G21, G23

\begin{abstract}
$\underline{\text { ABSTRACT }}$
This paper uses a new panel data set of credit card accounts to analyze credit card delinquency, personal bankruptcy, and the stability of credit risk models. We estimate duration models for default and assess the relative importance of different variables in predicting default. We investigate how the propensity to default has changed over time, disentangling the two leading explanations for the recent increase in default rates - a deterioration in the risk - composition of borrowers versus an increase in borrowers' willingness to default due to declines in default costs, including social, information, and legal costs. Even after controlling for risk-composition and other economic fundamentals, the propensity to default significantly increased between 1995 and 1997. By contrast, increases in credit limits and other changes in risk-composition explain only a small part of the change in default rates. Standard default models appear to have missed an important time-varying default factor, consistent with a decline in default costs.
\end{abstract}

David B. Gross

Lexecon, Inc.
Nicholas S. Souleles

Finance Department

The Wharton School

$2300 \mathrm{SH}-\mathrm{DH}$

University of Pennsylvania

Philadelphia, PA 19104-6367

and NBER 
Debt issued by consumers is an under-studied asset class. There has been particularly little academic study of recent trends in default on this debt. Between 1994 and 1997 the number of personal bankruptcy filings in the U.S. rose by about 75\%. The 1.35 million filings in 1997 represented well over $1 \%$ of U.S. households. Delinquency rates on credit cards rose almost as sharply. [Federal Reserve Board of Cleveland (1998)] The resulting losses to lenders amounted to a sizeable fraction of the interest payments they collect, potentially raising the average cost of credit. These trends in default, both in bankruptcy and delinquency, are especially surprising in light of the strong economy over the period. They provide an unusually rich source of variation to test the stability of models that forecast personal default and of credit risk models more generally.

There are two leading explanations for these trends. First, the risk-composition of borrowers might have worsened. Under the "risk effect," less credit-worthy borrowers obtained additional credit in recent years, and it is these borrowers who accounted for most of the rise in default. In particular, many analysts cite growth in the number of credit card offers and in the sizes of credit card limits, among other changes in the supply of consumer credit, as the most important factors behind the rise in default. (See e.g. the New York Times (1998).)

The second explanation focuses on the costs of default, including social, information, and legal costs. Default is often associated with social stigma, both non-pecuniary (e.g., disgrace) and pecuniary (e.g., the consequences of a bad reputation). Many analysts argue that these social costs have recently declined, as default has become more commonplace. Filing for bankruptcy also entails information and legal costs which might also have declined. Here analysts cite growth in the number of bankruptcy lawyers and their advertising (as prohibitions on advertising were loosened), as well as in other sources of advice like "how-to-file" books. Further, the flow of informal advice from family and friends might have accelerated as more people have been 
through bankruptcy. ${ }^{1,2}$ Even a small decline in these various costs could substantially increase default rates, considering White (1997)'s estimate that between $15 \%$ and $31 \%$ of U.S. households could benefit, just in terms of their current net worth, by filing for bankruptcy. Generalizing these arguments, by the "demand effect" we mean that people have become more willing to default over time, after controlling for their risk characteristics (which take into account the effects of changes in credit supply) and other standard economic fundamentals.

It is important to determine the relative significance of these two alternative explanations. Unlike the risk effect the demand effect represents a change in the relationship between default and the variables that lenders typically use to predict default, such as debt levels. Credit risk models would be missing some systematic and time-varying factor, and hence be unstable, potentially resulting in the misallocation or mispricing of credit. Unlike a deliberate expansion in the supply of credit, an unexpected decline in the costs of default would lead to greater credit losses than expected. ${ }^{3}$ While lenders can respond to increased losses from either the risk or demand effects by improving the risk-composition of their portfolios, a significant decline in default costs might require more substantial changes in lending standards. As regards public policy, some analysts subscribing to the risk effect have advocated restricting credit supply in order to improve the risk-composition of the borrowing population. Others, subscribing to the

\footnotetext{
${ }^{1}$ Weller (1998) provides a typical exposition of these arguments: "Just as attorney advertising has enhanced the public's awareness of bankruptcy as a financial escape hatch and bankruptcy reform has made filing less time consuming than renewing a driver's license, the stigma of bankruptcy has become a shadow of its former self. The names of good bankruptcy attorneys and stories about the ease of getting out of debt are passed around the water cooler like football scores on a Monday morning in October."

2 Another potential cost of default is reduced access to future credit and transactions services. Increases in postdefault credit, or increased information about such credit, is consistent with the demand effect. However, while there appears to have been an increase in subprime lending and secured credit cards (which are often provided postdefault) in the early 1990s, we are unaware of evidence that this form of credit substantially increased during our sample period. In fact, some analysts suggest that it might have declined in the later part of the period in response to increased losses in the earlier part. For an analysis of post-default access to credit, see Musto (2000).
} 
demand effect, have advocated making the terms of bankruptcy less attractive in order to increase the perceived costs of default.

Unfortunately, it has been difficult to disentangle the risk and demand effects empirically. First, it is not obvious how to operationalize the demand effect. The various costs of default, especially social, legal, and information costs, are inherently difficult to measure. Most of the proxies that have been suggested run into problems of endogeneity and reverse causality. ${ }^{4} \mathrm{~A}$ second difficulty is that controlling for risk-composition requires detailed measures of credit supply and credit risk for a large sample of borrowers, including a large number of borrowers who have defaulted. As in the literature on corporate default, traditional household data sets do not provide enough information.

This paper uses a new data set containing a panel of thousands of individual credit card accounts from several different card issuers. The data is of very high quality. It includes essentially everything that the issuers know about their accounts, including information from peoples' credit applications, monthly statements, and credit bureau reports. In particular, the data set records cardholder default (both delinquency and bankruptcy) and contains a rich set of measures of credit risk including debt levels, purchase and payment histories, credit lines, and credit risk scores, the issuers' own overall summary statistics for the risk of each account.

We use this data to analyze credit card delinquency and more broadly personal bankruptcy and the stability of credit risk models. Aggregate credit card debt currently amounts to over $\$ 500$ billion, much of which is securitized, so credit card default is of interest in itself.

\footnotetext{
${ }^{3}$ Many analysts appear to have been surprised by the rise in default rates and credit loses over the 1994-1997 period [Moody's (1997)].

${ }^{4}$ For example, consider using the number of advertisements by bankruptcy lawyers as an inverse proxy for information and legal costs. The problem is that an increase in ads might not be the cause of the rise in bankruptcies,
} 
Further, because about $75 \%$ of U.S. households hold credit cards, and our data set includes credit bureau variables pertaining to all sources of consumer credit, not just credit cards, we are able to study personal bankruptcy and default in general. Total consumer debt amounts to about $\$ 6 \mathrm{~T}$, \$1.3T excluding mortgages [Federal Reserve System (1999)]. Compared to the assets side of household balance sheets, there has been surprisingly little analysis to date of the liabilities side, largely for lack of data. Finally, empirical models of personal default and corporate default are in many ways analogous. On the corporate side, Saunders (1999) emphasizes the same two difficulties discussed above: the paucity of data, especially the limited number of observations of default; and the potential instability of default models over time, especially over the business cycle. In contrast, our data allows us to study a large number of defaulters over a concentrated sample period, 1995-1997, of benign macro-economic conditions. Finding model instability in such a sample would be a relatively strong result.

Specifically, we estimate duration models for default, for both credit card delinquency and personal bankruptcy, and assess the relative importance of different variables in predicting default. For instance, are younger accounts and accounts with larger credit lines more likely to default? The estimated models also allow us to evaluate the quality of commercial credit scores as predictors of bankruptcy and delinquency. Are the scores efficient predictors of default, incorporating all information available to issuers? Moreover, we investigate how the propensity to default has changed over time, disentangling the risk and demand effects. Since the data include the information that the card issuers themselves use to measure risk, we are able to control for all changes in the risk-composition of accounts that were observable by the issuers.

but rather their effect. The increased bankruptcies could be due to the risk effect, with lawyers responding to the increased demand for their services with additional advertising. 
This allows us to assess the stability of default models from the point of view of a lender trying to forecast default in his portfolio.

A key finding is that the relation between default and economic fundamentals appears to have substantially changed over the sample period. Even after controlling for risk-composition and other standard economic variables, the propensity to default significantly increased between 1995 and 1997. Ceteris paribus, a credit card holder in 1997 was almost 1 percentage point more likely to declare bankruptcy and 3 percentage points more likely to go delinquent than a cardholder with identical risk characteristics in 1995. These magnitudes are almost as large as if the entire population of cardholders had become one standard deviation riskier, as measured by credit risk scores. By contrast, increases in credit limits and other changes in risk-composition explain only a small part of the change in default rates over time. Standard default models appear to have missed an important, systematic and time-varying default factor, consistent with the demand effect.

Section 1 of the paper describes the data used in the analysis and Section 2 discusses related studies. Section 3 develops the econometric methodology and Section 4 reports the results. Conclusions appear in Section 5.

\section{Data Description}

The authors have assembled a panel data set of credit card accounts from several different credit card issuers. The accounts are representative of all open accounts in 1995. Because the issuers include some of the largest credit card companies in the U.S., the data should be generally 
representative of credit card accounts in the U.S. in $1995 .{ }^{5}$ The individual accounts are then followed monthly for two years or more, depending on the issuer. Different credit card issuers track somewhat different sets of variables at different frequencies depending on whether the variables come from cardholders' monthly statements, credit bureau reports, or credit applications. To protect the identity of the accounts and the issuers, the data from different issuers were pooled together, with great care taken to define variables consistently across issuers. The reported results will focus on variables common to all the issuers. However, the results were checked for robustness separately for each issuer, using that issuer's complete set of variables. Table 1 provides summary statistics for the main variables used below.

This data has a number of unique advantages compared to traditional household data sets like the Survey of Consumer Finances (SCF) or the Panel Study of Income Dynamics (PSID). First, the large cross-section of accounts contains thousands of observations of even low probability events like delinquency and bankruptcy. Second, the long time series makes it possible to estimate explicitly dynamic models of default. Third, in contrast to data based on surveys of households, measurement error is much less of a problem. Fourth, the data contains essentially all the variables used by issuers in evaluating accounts. Using account data does, however, entail a number of limitations. The main unit of analysis in the data is a credit card account, not an individual or a household. We partially circumvent this limitation by using data from the credit bureaus, which cover all sources of credit used by the account holder, and by examining account delinquency in addition to bankruptcy. Also, there is little information about some potentially important variables like household assets or employment status. However the

${ }^{5}$ As a check, the data were benchmarked against the more limited and self-reported credit card information in the 1995 Survey of Consumer Finances and the aggregate data on revolving consumer credit collected by the Federal 
issuers also lack access to this information, so its absence will not affect our identification strategy. Also, the study by Fay, Hurst, and White (1998) discussed below finds that the effects of such variables on bankruptcy are relatively small in magnitude.

\section{Related Studies}

Most empirical studies of default have focused on bankruptcy, concentrating on the effect of changes in the Bankruptcy Code in 1978 or on the effects of different exemption levels on filing rates across U.S. states. (For a review see Hynes (1998).) These studies have generally used aggregated data, and hence do not address the role of risk-composition.

In their historical discussion of bankruptcy, Moss and Johnson (1998) note that lower income households have gained increased access to credit over time. They argue that this "democratization" of credit can potentially explain the recent rise in bankruptcy. This argument is a version of the risk-composition effect. (See also Ausubel (1997).) Unfortunately the SCF, which Moss and Johnson use to document the change in the distribution of debt, does not record whether people have filed for bankruptcy so they are unable to test their argument empirically. Also, the amount of debt households carry is an endogenous variable, conflating credit demand and supply, and so cannot itself be said to "explain" default. ${ }^{6}$ Finally, since there have been changes in the income distribution of credit in the past, it does not follow that recent changes in credit supply explain current bankruptcy trends. The relative importance of risk-composition

Reserve. It appears that the SCF households underreport their credit card borrowing, perhaps to avoid perceived stigma. (See Gross and Souleles (2001).)

${ }^{6}$ In a companion paper, Gross and Souleles (2001), we explicitly distinguish credit demand and supply, identifying the response of credit card debt to changes in supply. 
versus other factors like default costs is a quantitative question that can only be answered with suitable data.

Domowitz and Sartain (1999) circumvent the limitations of the SCF by combining it with a separate data set of bankruptcy petitions. They use this additional data essentially to estimate whether the various households in the 1983 SCF have filed for bankruptcy, as a function of their demographic characteristics. However, it can be difficult to estimate low-probability events like bankruptcy in a small, cross-sectional sample like the SCF. ${ }^{7}$

The 1996 PSID contained a set of retrospective questions about bankruptcy. Fay, Hurst, and White (1998) use this data to identify the effects of social stigma. Because the PSID also recorded data on household balance sheets in a number of years (1984, 1989, and 1994), the authors are able to estimate for each household in their sample the economic benefit of filing for Chapter 7, taken to be the value of debt that would be discharged minus assets (net of exemption levels) that would be relinquished. As an inverse proxy for stigma or information costs, the authors use the lagged bankruptcy rate in the state in which the household resides. They find that the probability of filing increases with both the economic benefit of filing and the inverse proxy for stigma. However, the magnitude of the increase is small in both cases. This paper differs from the Fay, Hurst, and White study in a number of ways. First, their PSID sample contains only about 250 observations of bankruptcy over the course of a twelve-year period ending in 1995. Non-linear inference on such a small sample of households can be difficult. ${ }^{8}$ Second, the PSID

\footnotetext{
7 To illustrate, the SCF sub-sample used in their analysis contains about 1,900 households. Even at today's bankruptcy rate of approximately $1 \%$, which is much larger than the 1983 rate, the sub-sample would include only about 19 households that actually filed for bankruptcy.

${ }^{8}$ Fay, Hurst, and White estimate that their PSID households underreported the incidence of bankruptcy by about $50 \%$ relative to aggregate statistics.
} 
does not contain explicit measures of household credit risk like risk scores, nor measures of credit supply like credit lines. Third, we estimate explicitly dynamic duration models for default.

Ausubel (1999) uses data from a credit card issuer to analyze interesting marketing experiments that varied the terms of credit card offers. He finds evidence of adverse selection in the pools of applicants responding to different offers, in both their observed characteristics and their subsequent default risk. However, he does not address the questions of interest here, such as the relative importance of the risk and demand effects, in part because his data includes only a single "cohort" of accounts. ${ }^{9}$

The related literature on corporate default is much larger, though as already noted it too has been constrained by data limitations. Also, as Shumway (1998) emphasizes, much of the literature has used static, cross-sectional specifications for default. By contrast the duration analysis used here will explicitly accommodate changes over time in the riskiness of a given borrower.

\section{Econometric Methodology}

From the data set described in Section 1, we drew a representative sample of all credit card accounts open as of June 1995, excluding only accounts that had been closed or frozen on or before June 1995 because they were already bankrupt or three or more cycles delinquent. ${ }^{10,11}$

\footnotetext{
${ }^{9}$ Hence the specified models of default are static and cannot analyze the risk-composition of different cohorts of credit card accounts. Also, they cannot distinguish the time and seasoning (age of account) effects that will play important roles below, because time and seasoning are perfectly collinear for a single cohort.

10 This makes the data stationary. The accounts already two cycles delinquent in June 1995 can go three cycles delinquent immediately in the following month. While accounts that are one or zero cycles delinquent in June 1995 must wait at least one or two months respectively before going three cycles delinquent, this is true in subsequent months as well. Account holders can go bankrupt in any month. We also re-ran the main specifications dropping the first and the first two quarters of data. The results were consistent with the results reported in the text.
} 
These accounts are followed for the next 24 months, or until they first default or attrite in good standing. ${ }^{12}$ This period from 1995:Q3 through 1997:Q2 covers the time of the sharp rise in default at the national level. Two indicator variables were created that identify the first month in the sample, if any, in which an account defaulted. The delinquency indicator, DEL, identifies the first time that an account failed to meet its minimum payment for three successive months, the standard industry definition of serious delinquency. The bankruptcy indicator, BK, identifies the month in which the card issuer was notified or learned from the credit bureaus that the cardholder filed for bankruptcy. Accounts that are both delinquent and bankrupt are counted as bankrupt. ${ }^{13}$ This yields about four thousand accounts going bankrupt and fourteen thousand accounts going delinquent. A random sample of about ten thousand accounts that never default within the sample period is included as a control group. The delinquent and the bankrupt accounts are each separately compared to the non-default control group. The resulting samples overweight defaulting accounts, in predetermined proportions, in order to increase precision. All the results below are weighted to make them representative.

We estimate dynamic probit models for default that are equivalent to discrete duration models [Shumway (1998), Hoynes (1999)]. For either the delinquency or bankruptcy sample, let $D_{i, t}$ indicate whether account $i$ defaulted in month $t$. For instance an account that goes three cycles delinquent in month 10 would have $D_{i i}=0$ for the first nine months, $D_{i, 10}=1$, and then drop

\footnotetext{
${ }^{11}$ To simplify the analysis of the age of a credit card account below, the main analysis excludes accounts opened before 1990. Given the recent growth in the number of accounts, this restriction retains most accounts. The conclusions below are unaffected whether or not these older accounts are included.

${ }^{12}$ About one fifth of the accounts attrite in good standing before the end of the sample period. Their characteristics are similar to those of the accounts that last until the end of the sample; for example, their credit scores are only a few points lower. The duration models we estimate allow for such attrition. As a check, we re-ran the main specifications dropping these attritors from the entire sample, and verified that our conclusions did not change.

13 Of the bankrupt accounts, about one fifth never went delinquent, half went delinquent before bankrupt, and the rest went delinquent and bankrupt together. When bankruptcy followed delinquency it usually followed within a
} 
out of the sample. Let $D_{i, t}^{*}$ be the corresponding latent index value. The main specification that will be estimated is given by Eq. (1):

$$
D_{i, t}^{*}=b_{0}^{\prime} \text { time }_{t}+b_{1}^{\prime} \text { age }_{i, t}+b_{2}^{\prime} \text { risk }_{i, t}+b_{3}^{\prime} \text { econ }_{i, t}+\eta_{i, t} \text {. }
$$

age $_{i, t}$ represents the number of months that account $i$ has been open by time $t$. This variable allows for "seasoning" of credit card accounts. For instance, accounts might become less likely to default as they age. Under the duration model interpretation of Eq. (1), it is $a g e_{i, t}$ that allows the hazard rate for default to vary with duration (duration-dependence). The vector $\boldsymbol{a g} \boldsymbol{e}_{\boldsymbol{i}, t}$ represents a fifth-order polynomial in account age, to allow the associated hazard function to vary nonparametrically. $\boldsymbol{r i s k}_{i, t}$ and $\boldsymbol{e c o n}_{i, t}$ represent account-specific measures of risk and local economic conditions, respectively, and will be further described below. The time dummies time $\boldsymbol{t}_{\boldsymbol{t}}$ corresponding to calendar quarters, allow for shifts over time in the average propensity to default, for accounts of any age and risk characteristics and controlling for economic conditions. They capture any other time-varying default factors.

It will be helpful to begin with a simpler specification. A probit model of delinquency was first estimated with only the time dummies and the fifth-order polynomial in account age as the independent variables, omitting $\boldsymbol{r i s k}_{i, t}$ and $\boldsymbol{e c o n}_{i, t}$. Figure 1 displays the resulting predicted values. Each curve shows the effect of account age (seasoning) on the probability of delinquency, i.e. the non-parametric hazard function, for a different quarter. The underlying age variables are both statistically and economically significant. The inverted-U shape suggests that the probability of delinquency rises from the time an account is booked until about its two-year birthday, and then declines. The coefficients on the time dummies are also significant and generally increasing 
over time, though not completely monotonic. This suggests that the hazard functions shifted over time, and so the simple specification is unstable.

It is tempting to interpret these shifts as reflecting the demand effect, due to changes in people's willingness to default. However, the shifts could instead reflect changes over time in the risk-composition of accounts, due to changes in credit supply, or in other economic fundamentals. For instance if lending standards were loosened over time, recently booked accounts might be riskier, raising the average default rate. To illustrate, we re-estimated the simple probit model replacing the time dummies with "cohort" or vintage dummies reflecting the time at which each account was opened. For instance the 1990 cohort is composed of the accounts that were opened in 1990. Figure 2 shows the predicted values, with each curve now representing the age hazard-function for a given cohort, over the period in which that cohort appears in the sample. ${ }^{14}$ The effect of age is similar to that in Figure 1, with the hazard rate peaking at about two years. But for a given age, the younger cohorts (to the left in the figure) are more likely to go delinquent than the older cohorts (at the bottom right).

At first glance these results seem to support the risk effect, since recent cohorts of accounts appear to be riskier. ${ }^{15}$ However, the results do not rule out the possibility that all cohorts, not just the recent cohorts, became increasingly likely to default in recent years. In fact, Figures 1 and 2 are statistically equivalent because of the "life cycle" identity that links the month in which an account is opened (represented by its cohort), the age of the account, and the

\footnotetext{
14 The cohort dummies are for 1990, 1991, 1992, the first and second halves of 1993 and 1994, and the first half of 1995. The curve furthest to the "south-east" represents the 1990 cohort, which was already over 50 months old at the beginning of the sample in 1995 and is then followed for the 24 months of the sample period. The curve furthest to the "west" represents accounts opened in the first part of 1995, which are only a few months old at the start of the sample and are also followed for the 24 months of the sample period.

15 Also, the younger cohorts start the sample with lower credit scores on average than the older cohorts. However this difference largely reflects the seasoning effects prominent in the figures.
} 
current month. Since the opening date plus age equals time, the two specifications underlying the figures are collinear. ${ }^{16}$

Eq. (1) avoids this identification problem by replacing the cohort dummies with accountspecific measures of risk, $\boldsymbol{r i s k}_{i, t}$, which are not collinear with age and time. These measures provide a more complete specification of risk at the individual account level, while still capturing differences in average risk characteristics at the cohort level. The reason that different cohorts have different average probabilities of default is that there are different fractions of risky accounts in each cohort, so what matters is the riskiness of the individual accounts. The available risk measures are quite comprehensive. They include direct, monthly observations of the performance of each account, such as debt levels, purchase and payment histories, and credit lines, as well as the credit risk scores, the issuers' own summary of the riskiness of each account. We will assess the relative importance of these variables in predicting default. Note that if the credit scores are sufficient statistics for default, no other variables available to the issuers should be significant predictors given the scores. Furthermore, $\boldsymbol{e c o n}_{i, t}$ controls for local economic conditions like the unemployment rate, per capita income, and the poverty rate in the state in which the account holder resides (unemployment, average_income, and poverty_rate, respectively); the fraction of people in the state without health insurance (no_insurance), and the median real new house price in the corresponding census region (house_prices). While unemployment is available monthly, house_prices and average_income are measured quarterly,

\footnotetext{
${ }^{16}$ Consider the following example. Suppose one observes that the 1995 cohort had a greater default rate when it was 2 years old (in 1997) than the 1990 cohort had when it was 2 years old (in 1992). This could be due to a cohort effect, if the 1995 cohort was riskier, at any age, than the 1990 cohort, as suggested by Figure 2. Alternatively, this could be due to a time effect, if all accounts in 1997 were more likely to default than were accounts in 1992, whatever their cohort and age, as suggested by Figure 1.
} 
and no_insurance and poverty_rate only annually. Monthly values for the latter four variables were linearly interpolated. $^{17}$

The age polynomial and the risk measures $\boldsymbol{r i s}_{\boldsymbol{i}, t}$ together control for the risk-composition of credit card accounts and therefore for the risk effect. If recently booked accounts have sufficiently worse risk characteristics, this could explain the rise in default, as under the risk effect. The time dummies identify changes over time in the average propensity to default that are not due to risk-composition or other economic fundamentals. Hence the time dummies capture the demand effect, including omitted factors like changes in default costs which affect people's willingness to default. It is of course possible that the time dummies are picking up some other measure of risk or other economic fundamental that we have not controlled for. However, Eq. (1) already contains a much richer set of controls than is available in the data used in previous studies. In particular, the controls include the variables tracked by the card issuers themselves, who have strong incentives to measure risk accurately, and thereby control for credit supply. Further, in light of the strength of the economy over the sample period, most other unmeasured economic fundamentals improved over time and therefore would be unlikely to increase default rates.

There are multiple possible timing conventions that could be used for the risk controls risk $_{i, t}$ in Eq. (1). To identify changes in booking standards over time, they might naturally be taken from the original time of application. However, application data would not control for

\footnotetext{
${ }^{17}$ We also considered median family income and the divorce rate in each state, both available only annually. Median income was generally insignificant, and since average_income is available at higher frequency we use the latter instead in the reported specifications. The coefficient on the divorce rate was significantly positive in the bankruptcy models below, but did not quantitatively change the marginal effects measured by Eqs. (2) and (3). The divorce rate was insignificant in the delinquency models however. Because the divorce variable (which comes from the Department of Health and Human Services) is missing for a number of states, we do not include it in the reported specifications. We verified that omitting it does not change our conclusions.
} 
changes in risk-composition or economic conditions between the time of application and the start of the sample. For example, the 1990-91 recession might have had lingering effects on people's ability to pay their debts. Taking the risk controls from the time of application would attribute all of this variation to the demand effect. Also, some issuers did not store some of their application variables, especially for the older accounts.

Instead, for the main results the risk controls are all taken from June 1995, the month before the start of the sample period (that is, month $t=0$ ). While the polynomial age $\boldsymbol{a}_{i, t}$ nonparametrically controls for the time-varying component of account risk, $\boldsymbol{r i s}_{i, 0}$ controls for the fixed component, more completely than the fixed cohort dummies used in Figure 2. Formally, $\boldsymbol{a g e}_{i, t}$ allows for duration-dependence in the baseline hazard function: the (conditional) probability of default can vary over time as account $i$, of fixed characteristics risk $\boldsymbol{k}_{i, 0}$, ages. risk $_{i, 0}$ allows this hazard function to shift across accounts that start the sample period with different risk characteristics. ${ }^{18}$ In extensions we will also interact $\boldsymbol{a g} \boldsymbol{e}_{i, t}$ and $\boldsymbol{r i s k}_{i, 0}$, which will allow the hazard functions to have non-parametrically different shapes across the different risk groups.

Given this specification, to test for the risk effect we will essentially check whether the sample trends in default can be explained by riskier accounts progressing through the riskier parts of their life cycle (e.g., around their two-year birthday). For instance, suppose that many of the youngest accounts in the sample, those opened in early 1995, have bad risk characteristics risk $\boldsymbol{k}_{i, 0}$. Then, ceteris paribus, the default rate might have increased in 1997 because the risky (and

${ }^{18}$ More formally, let $g(a)$ be a fifth-order polynomial in account age $a$, in months, corresponding to age $\mathbf{e}_{i, t}$ The hazard function $\lambda_{i}(a) \equiv \operatorname{Pr}\left(\mathrm{D}_{i, a}=1 \mid \mathrm{D}_{i, a-l}=0\right)$ is the probability of defaulting at age $a$ conditional on not having defaulted before. Eq. (1) implies that $\lambda_{i, t}(a)=\lambda\left(\mathbf{b}_{\mathbf{0}}{ }^{\prime}\right.$ time $\left._{t}+g(a)+\mathbf{b}_{\mathbf{2}}{ }^{\prime} \boldsymbol{r i s}_{i, 0}+\mathbf{b}_{\mathbf{3}}{ }^{\prime} \boldsymbol{e c o n}_{i, t}\right)$, where the functional form $\lambda()$ depends on whether we are using the probit or logit estimator. Thus the hazard function is allowed to vary with both age $a$ and the risk characteristics $\boldsymbol{r i s k}_{i, 0}$, as well as with time and economic conditions. Such a specification of the hazard function is standard in the literatures on the duration of unemployment and welfare spells. There the 
relatively large) 1995 cohort of accounts hit its two-year birthday in 1997. By contrast, to test for the demand effect, we will check whether all accounts - even accounts with the same risk characteristics, age, and other economic fundamentals - have become more likely to default over time. Using $\boldsymbol{r i s k}_{i, 0}$ is also appropriate from the point of view of a lender (or investor) who at time 0 is trying to forecast future default rates in a portfolio. Forecasting over a two-year horizon is consistent with industry practice; in particular the credit risk scores are usually calibrated on twoyear samples.

Another possible timing convention would be to use updated, contemporary risk controls, $\boldsymbol{r i s k}_{i, t}$. But updating the risk controls would confound the risk and demand effects because many of the risk variables are under the direct control of the account holder. For instance, people could have chosen to take on more debt over the course of the sample period because the stigma of default has fallen. Using $\boldsymbol{r i s k}_{i, t}$ would attribute all of this variation to the risk effect, thereby understating the demand effect. One of the variables in $\boldsymbol{r i s}_{i, t}$, however, is directly under the control of the issuers, namely the credit line. Therefore we sometimes replace the initial line, $\operatorname{line}_{i, 0}$, with the updated line (once lagged), line $e_{i, t-1}$, keeping the other, demand-determined risk controls at their initial $(t=0)$ values. This allows us to test whether increases in credit lines - the intensive margin of credit supply - have contributed to the default rate during the sample period. ${ }^{19}$

At the national level, credit supply also changed during the sample period along the extensive margin, through the introduction of new accounts. Since our sample is representative of accounts already open in mid 1995, it does not include accounts that opened subsequently. unemployed person, usually time-invariant demographic variables like gender and race. (See e.g. Hoynes (1999).) 
Hence the results do not include the contribution of these youngest accounts to national default rates between mid 1995 and mid 1997. However, this is not a problem for our analysis. The demand effect should be similar across different accounts, and the results will fully capture the contribution of the risk-composition of the accounts that are in the sample, to the default rates in the sample.

Both dynamic probit and logit models of Eq. (1) were estimated. Because the results were both qualitatively and quantitatively similar, we report only the probit results. The standard errors allow for heteroscedasticity across accounts as well as serial correlation within accounts. Dummy variables for the issuers are included but not reported. Various extensions of Eq. (1) will also be considered.

To evaluate quantitatively how changes in the risk and demand effects influenced the probability of default, we want to compute the marginal value of varying each effect independently, at different times in the sample period. This requires a generalization of the marginal effects that are usually computed [e.g., Greene (1991), p. 664]. Let $\Phi$ be the normal $\mathrm{CDF}$ (for the probit specification), and for any variable $x$ let $\overline{x_{i, t}}=\frac{1}{N} \sum_{i=1}^{N} x_{i, t}$ be the cross-sectional mean of $x$ in quarter $t$. We can naturally define the marginal value of the demand effect to be the effect on default rates of varying only the time dummies, holding all other variables in Eq. (1), which control for credit supply and other aspects of risk-composition, equal to their crosssectional means. As a baseline, marginal values will be calculated relative to the first quarter (1995:Q3). Thus, the marginal effect of the change in the demand effect between quarter 1 and quarter $\mathrm{t}$ is calculated as

${ }^{19}$ Of course the issuers endogenously choose the credit lines on the basis of account holders' past behavior, so using 


$$
\begin{aligned}
\text { demand }_{t}= & \Phi\left(b_{0}^{\prime} \text { time }_{t}+b_{1}^{\prime} \overline{\operatorname{age}_{i, 1}}+b_{2}^{\prime} \overline{\text { ris }_{i, 0}}+b_{3}^{\prime} \overline{\text { econ }_{i, 1}}\right)- \\
& \Phi\left(b_{0}^{\prime} \text { time }_{1}+b_{1}^{\prime} \overline{\operatorname{age}_{i, 1}}+b_{2}^{\prime} \overline{\text { risk }_{i, 0}}+b_{3}^{\prime} \overline{\text { econ }_{i, 1}}\right)
\end{aligned}
$$

Symmetrically, we define the marginal effect of changing risk-composition over time to be the effect of varying all variables other than the time dummies, again evaluating at cross-sectional means:

$$
\begin{aligned}
\text { riskcomp }_{t}= & \Phi\left(\text { b }_{0}^{\prime} \text { time }_{1}+b_{1}^{\prime} \overline{\text { age }_{i, t}}+b_{2}^{\prime} \overline{\text { risk }_{i, 0}}+b_{3}^{\prime} \overline{\text { econ }_{i, t}}\right)- \\
& \Phi\left(b_{0}^{\prime} \text { time }_{1}+b_{1}^{\prime} \overline{\text { age }_{i, 1}}+b_{2}^{\prime} \overline{\text { risk }_{i, 0}}+b_{3}^{\prime} \overline{\text { econ }_{i, 1}}\right)
\end{aligned}
$$

Standard errors for demand and $_{\text {riskcomp }}$ are calculated using the delta method.

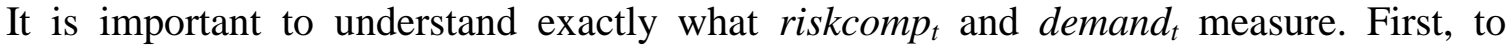
emphasize the difference between changes in the demand effect and changes in standard economic fundamentals, we include in riskcomp ${ }_{t}$ the effects of changes in economic conditions, by varying $\boldsymbol{e c o n}_{i, t}$. Second, since $\boldsymbol{r i s k}_{i, 0}$ identifies the fixed component of each account's risk, it does not directly contribute to variation in risk-composition over the sample period. As a result,

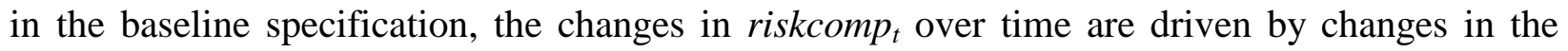
variable, hazard-rate component of risk-composition, $\boldsymbol{a g} \boldsymbol{e}_{i, t}$, and in $\boldsymbol{e c o n}_{i, t}$. Once we have used $\boldsymbol{r i s k}_{i, 0}$ to control for the fixed component of account risk, our identification scheme allows us to treat the marginal effects of risk and demand symmetrically, by using the polynomial in duration $\boldsymbol{a g} \boldsymbol{e}_{i, t}$ to control for changes in risk over time, and the dummy variables $\boldsymbol{t i m e}_{\boldsymbol{t}}$ to measure changes 
in the demand effect over time. For a given risk group, identified by the account-specific measures of risk in $\boldsymbol{r i s k}_{i, 0}$, both age and time are allowed to have a non-parametric effect on the probability of default over time.

\section{Results}

Column (1) of Table 2 shows the baseline results from the probit model for bankruptcy. The estimated coefficients for the quarter dummies and age polynomial are followed by the coefficients for the risk controls and local economic conditions. Starting with the latter at the bottom of the column, the unemployment rate unemployment and house prices house_prices are significant with the expected signs: greater unemployment and weaker house prices are associated with more bankruptcies. The risk controls are jointly very significant. Because the credit scores are important summary statistics for risk, both their levels and squares are included. The issuers estimate the scores using all the information at their disposal, both in-house (the "internal" scores, based on the past behavior of the individual account) and at the credit bureaus (the "external" scores, based on the behavior of the account holder across all sources of credit). We use both scores. For each score the linear and quadratic terms are together quite significant, with $\chi_{(2)}^{2}$ statistics well over 100 . Their total effect has the expected sign: accounts with higher scores are much less likely to go bankrupt. The remaining risk controls include account total balances, payments, and purchases, all normalized by the credit line, and the line itself. The normalized balance, defined as the utilization rate, is specified flexibly as a series of dummy variables: utilization1 to utilization7 represent a utilization rate of 0 , in $(0,0.4],(0.4,0.7]$, 
$(0.7,0.8],(0.8,0.9]$, and $(0.9,1.0]$, and over 1.0 , respectively. ${ }^{20}$ Not surprisingly, accounts with higher utilization rates are much more likely to go bankrupt. Accounts making smaller payments or larger purchases also go bankrupt more often, although the latter effect is not significant. Since variables other than the credit scores are statistically significant, the scores appear to be inefficient predictors of default. The coefficient on the line is insignificant, but will be discussed further below, along with additional risk controls. The age variables are jointly significant, with the associated age hazard function rising for young accounts but then flattening out compared to Figure 1.

As for the time dummies, their coefficients are highly significant and increase monotonically. Thus, even after controlling for account age, balance, purchase and payment history, credit line, risk scores, and economic conditions, a given account was more likely to go bankrupt in 1996 and 1997 than in 1995. Some other systematic default factor must have deteriorated, consistent with the demand effect.

To quantify the relative importance of the risk and demand effects over time, we compute their marginal values, riskcomp $p_{t}$ and demand $_{t}$, for each quarter. The results appear in column (1) of Table 3, and are graphed in Figure 3. riskcomp ${ }_{t}$ is initially flat and then declines. As expected the aging of the portfolio and improvements in economic conditions imply a decrease in the bankruptcy rate over time. The time dummies essentially capture the difference between this implied bankruptcy rate and the actual rate in the sample. The rising trend in demand $_{t}$ suggests that the actual rate is increasingly larger than the implied rate. The magnitudes are much larger than for riskcomp t $_{t}$ and are statistically and economically significant. The probability of bankruptcy in quarter eight is about 0.06 percentage points per month larger than at the start of

\footnotetext{
${ }^{20}$ Because the credit limit constrains the magnitude of total balances, including transactions balances, not just debt,
} 
the sample. At an annual rate this translates to more than a 0.7 percentage point increase in the bankruptcy rate, ceteris paribus, a substantial effect.

Another way to illustrate the magnitude of the demand effect is to contrast it with the effect of reducing the credit score of every account in the sample by one standard deviation. This represents a very large increase in the overall riskiness of the sample portfolio of credit cards. A one standard deviation decrease in the internal risk score raises the average probability of bankruptcy by about 0.10 percentage points per month, not very much larger than the peak value of demand $_{t}$ in quarter eight. Thus, the estimated demand effect increased the bankruptcy rate by almost as much as had the entire portfolio become one standard deviation riskier - again a substantial effect. We similarly computed the effects of varying the other risk controls. The values for demand $_{t}$ are always large in comparison.

The remaining columns of Table 2 present various extensions of this analysis of bankruptcy. The associated marginal effects appear in the corresponding columns in Table 3. Column (2) shows the effects of interacting the age polynomial with all of the risk controls $\boldsymbol{r i s k}_{i, 0}$, which allows the hazard functions to have non-parametrically different shapes across different risk groups. ${ }^{21}$ The coefficients reported in Table 2 are for the primary, non-interacted variables. The interaction terms are significant for utilization, payments, purchases, and the

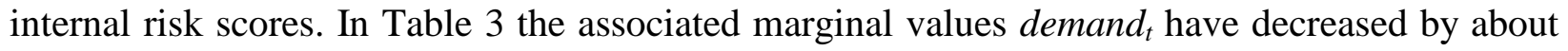
one-quarter in magnitude relative to baseline column (1), but they remain significant and continue to rise over time. The marginal values riskcomp now rise slightly through quarter 4 but then decline.

we include total balances in the numerator of utilization. The results are similar using just debt in the numerator. 
Turning to the intensive margin of credit supply, credit lines increased substantially over the sample period, on average over $60 \%$. Column (3) in Tables 2 and 3 shows the results of adding to Eq. (1) the updated credit line, line $_{i, t-1}$. The other, demand-determined risk controls are maintained at their initial values. The coefficient on the credit line is significant but negative, implying that larger lines are associated with less default. This reflects the fact that issuers offered greater amounts of credit to the people that they expected to be less risky. The coefficients on the time dummies and their marginal values demand $d_{t}$ do not change very much. These findings suggest that larger credit lines were not responsible for the recent rise in default. ${ }^{22}$

Column (4) extends this analysis by updating all of the risk controls, using $\boldsymbol{r i s}_{i, t-j}$ for a fixed number of lags $j$. Although this extension confounds the risk and demand effects by attributing some demand-related changes in default rates to the risk controls, it is still interesting for comparative purposes. However it is not clear how many lags $j$ would be most appropriate. In the year or so before default, many people significantly increase their debt (e.g. utilization rates often asymptote to $100 \%$ ) and miss payments. Hence using a very small $j$ would make $\boldsymbol{r i s k}_{i, t-j}$ statistically very informative, but economically irrelevant, since lenders need to predict default earlier than just a few months in advance, before debt increases. In practice lenders often forecast over 24 month horizons. But using $\boldsymbol{r i s k}_{i, t-24}$ would eliminate all but the final month of the sample. As a compromise we use $j=6$ lags, adding risk $_{i, t-6}$ to Eq. (1), at the cost of dropping quarters one and two of the sample period.

${ }^{21}$ For computational ease and to minimize collinearity in the interaction terms, the reported results interact risk $\boldsymbol{k}_{i, 0}$ with a quadratic polynomial in age, and use a quadratic function of utilization in risk $\boldsymbol{k}_{i, 0}$ instead of the six dummy variables. The results are similar using the fifth-order polynomial in age and the utilization dummies variables.

${ }^{22}$ For a subset of accounts we have credit bureau data on the number of other credit cards the account holder has. The average account holder opened about one new account over the sample period. We added this variable, once lagged, to Eq. (1). For bankruptcy, its coefficient was significantly positive; however the marginal values demand $_{t}$ declined by only about five percent in magnitude. For delinquency, below, its coefficient was significantly negative 
The results are reported in column (4). The coefficients are qualitatively similar to the baseline results in column (1), though, not surprisingly, much more significant. ${ }^{23}$ Nonetheless the time dummies and their marginal values demand $_{t}$ remain jointly quite significant and generally increasing. To interpret their magnitude, note that having dropped the first two quarters from the sample, the omitted time dummy is for quarter 3. Hence the marginals demand $t_{t}$ in column (4) of Table 3 can be compared to the differences $\left(\right.$ demand $_{t}-$ demand $\left._{3}\right)$ from column (1). In column (4) the peak value of demand $_{t}$ in quarter 8 is $.018 \%$, almost half the size of the corresponding value in column (1) of $.043 \%(=.060 \%-.017 \%){ }^{24}$ This decline in the magnitude of demand $_{t}$ is not surprising since risk $_{i, t-6}$ incorporates borrowers' risky behavior within the sample period. However, since this behavior is endogenous, using $\boldsymbol{r i s}_{i, t-6}$ does not help identify the cause of the trends in default in the sample; it merely reflects them, confounding the risk and demand effects. As already noted, people might have taken on more debt over the sample period and then defaulted because the costs of default had decreased.

Column (5) adds dummy variables for the state in which the cardholder resides. These variables control for fixed geographical effects on the propensity to default. For instance, additional credit might have recently been obtained by riskier households living in poorer areas. Similarly, regulations, judicial attitudes, and average household demographics, as well as default

\footnotetext{
by contrast. Note that the number of credit cards a person holds incorporates both supply effects and demand effects (i.e., the person's decision to accept credit card offers).

${ }^{23}$ The t-ratios for high levels of utilization are above 10 , the $\chi_{(2)}^{2}$ statistic for the significance of the internal scores has almost doubled, and the pseudo $\mathrm{R}^{2}$ has increased by almost $50 \%$. The results are similar on controlling for possible drift in the scores by normalizing them by the average score in the month.

${ }^{24}$ Dropping the first two quarters but still using risk $_{i, 0}$, as opposed to risk $_{i, t-6}$, resulted in a peak value for demand ${ }_{t}$ of about $.045 \%$, consistent with the original results in column (1).
} 
costs like stigma, can differ across states. The state dummies are jointly quite significant (not shown), but nonetheless slightly raise the magnitudes of demand $_{t}{ }^{25}$

As discussed above, it is difficult to operationalize more directly the various notions of the demand effect that have been proposed. Some of these emphasize the idea that social stigma and information about bankruptcy might change with the number of people in one's community, appropriately defined, that have already filed for bankruptcy. To operationalize this geographic view of default costs we use the aggregate bankruptcy rate in the state in which the cardholder resides. Column (6) adds to Eq. (1) the average of this rate over the previous two calendar quarters, denoted by staterate $_{t-1}$, plus its square. These variables are quite significant and their total effect is positive, as expected. The probability that someone files for bankruptcy increases with the number of people in her state who filed in the recent past. Furthermore, the marginal

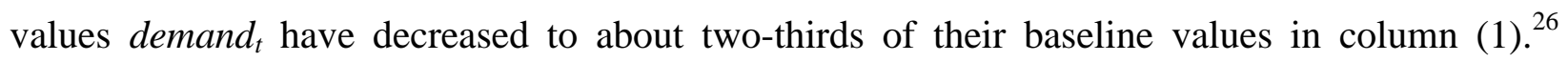
These results support the geographic view of default costs. The omitted default factor varies systematically across states. Of course, the relevant community within which stigma operates and information flows might not be one's state, so these results can be considered a lower bound for their effect.

The same analysis was undertaken using account delinquency instead of bankruptcy as the indicator of default. Tables 4 and 5 present the results for the different specifications and their corresponding marginal values. In the baseline specification, in column (1), the pattern of coefficients on the risk controls is similar to that above for bankruptcy. Now no_insurance is

\footnotetext{
${ }^{25}$ A conditional logit model was estimated to remove fixed effects by zip code, as well. The results were similar.

${ }^{26}$ We also added one, two, and six month's worth of lags of $\boldsymbol{e c o n}_{i, t}$ to this and the other main specifications. For bankruptcy these lags were generally insignificant and had very little effect on the demand $t_{t}$ marginals and the significance of staterate $_{t-1}$. For delinquency, below, a few of the lags were significant (though unstable in sign) but again had little effect on demand $_{t}$.
} 
significant, with lack of health insurance associated with more delinquency. Once again people with larger balances and lower risk scores are much more likely to default. Even with these controls for risk, the coefficients on the time dummies are again highly significant. Figure 4

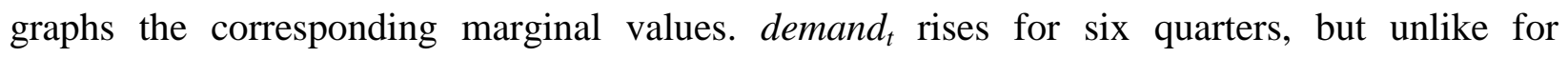
bankruptcy it then plateaus. (The magnitudes are larger than in Figure 3 because delinquency is more common than bankruptcy.) The peak value in quarter six of about 0.21 translates into almost a 3 percentage point increase in the annual delinquency rate, ceteris paribus. For comparison, decreasing the internal credit scores by one standard deviation raises the average predicted probability of delinquency by about 0.5 percentage points per month, about double the peak value of demand .

The remaining columns in Tables 4 and 5 present various extensions. Column (2) shows the results on interacting $\boldsymbol{a g}_{i, t}$ with $\boldsymbol{r i s k}_{i, 0}$. The interaction terms are significant for payments, purchases, and the internal scores. Again the time dummies remain significant and retain their original pattern, and their marginal values demand $d_{t}$ have been reduced by about one-fifth in magnitude. In column (3) the updated credit line line $_{i, t-1}$ is again significantly negative. In column (4) the updated risk controls risk $_{i,-6}$ are again very significant and reduce the magnitudes of demand $_{t}$ by well over half relative to $\left(\right.$ demand $_{t}-$ demand $\left._{3}\right)$ in column (1). (The linear and quadratic terms for the external score are jointly very significant.) Finally, adding state dummies does not substantially change the results, as reported in column (5).

For both bankruptcy and delinquency, for each issuer we added its complete set of available risk controls to Eq. (1). These often include variables like the income and age of the account holder (from the credit card application), and credit bureau variables like the total number of credit cards held by the account holder. While such variables are often significant in 
predicting default, they are less significant than the credit scores and utilization, and the coefficients on the time dummies always remain significant and generally increasing. ${ }^{27,28}$ It appears that there has not been enough change in risk-composition to explain the variation in default rates over the sample period. These results are consistent with the demand effect.

\section{Conclusion}

This paper used a unique new panel data set of credit card accounts to analyze credit card delinquency and more generally personal bankruptcy and the stability of credit risk models. We estimated duration models for consumer default and assessed the relative importance of different variables in predicting default. We also investigated how the propensity to default has changed over time, disentangling the two leading explanations for the recent increase in default - changes in risk-composition versus the demand effect, namely an increase in borrowers' willingness to default due to declines in default costs, including social, information, and legal costs. Our data contains a much richer set of measures of risk-composition than previously available, including debt levels, purchase and payment histories, credit lines, and credit risk scores. Since these measures include the information that credit card issuers themselves use to measure risk, we were able to control for all changes in credit supply and risk-composition that were observable by the issuers, including increases in credit lines.

${ }^{27}$ For example, for bankruptcy both account-holder age and income have a negative coefficient, but are not significant given the other covariates. (We first deflated application income to constant dollars, and then applied a real growth rate of $2.5 \%$ per year to allow for income growth between the time of application and the sample.) In

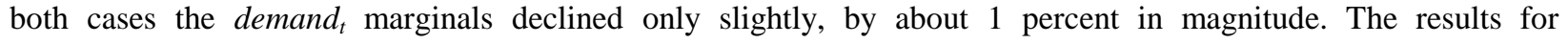
delinquency were similar, though the negative coefficient on age was significant.

${ }^{28}$ We also interacted the quarter dummies with an indicator for having high income (above the median). The trend in the time dummies was somewhat smaller in magnitude for the high income account holders than for the others, but 
The risk controls were highly significant in predicting both bankruptcy and delinquency. Accounts with lower credit scores were much more likely to default. Even controlling for the scores, accounts with larger balances and purchases, or smaller payments, were also more likely to default. Default also increased with unemployment, weak house prices, and lack of health insurance. Larger credit lines however were not associated with default, suggesting that issuers extended the larger lines to less risky accounts. Nonetheless, despite their significance, these variables explain only a small part of the change in bankruptcy and delinquency rates over the sample period. In sum, neither the risk-composition of accounts nor economic conditions changed enough to explain the trends in default rates.

Instead, the relation between default and economic fundamentals appears to have substantially changed over the period. Even after controlling for risk-composition and other economic fundamentals, the propensity to default significantly increased between mid 1995 and mid 1997. Ceteris paribus, a credit card holder in 1997 was almost 1 percentage point more likely to declare bankruptcy and 3 percentage points more likely to go delinquent than a cardholder with identical risk characteristics in 1995. These magnitudes are almost as large as if the entire population of cardholders had become one standard deviation riskier, as measured by risk scores. Standard default models appear to have missed an important, systematic and timevarying default factor. Because this factor is not explained by our very rich set of controls for risk and credit supply, nor by other economic fundamentals, these results are consistent with the demand effect.

While our analysis rules out the risk effect, it does not directly identify what underlies the estimated demand effect. The fact that the omitted default factor rises with the number of people

not significantly so. However, these interaction terms are hard to interpret in our empirical framework because they 
in one's state who have previously filed for bankruptcy is suggestive of a decline in social stigma or information costs, but is not conclusive. Further, the demand and risk effects can be interrelated. It is possible, for instance, that a previous deterioration in risk-composition or economic fundamentals caused a critical mass of people to declare bankruptcy, leading in turn to a reduction in default costs. This suggests the possibility of multiple equilibria in default rates. Also, lenders would likely respond to the demand effect by tightening lending standards and so improving the risk-composition of borrowers. Furthermore, our analysis does not provide a forecast about the future path of default. Nevertheless, if the demand effect is due to recent reductions in social or information costs, it will most likely be difficult to return the bankruptcy rate back to its previous levels before the 1990s, without a substantial tightening in lending standards or the bankruptcy code. ${ }^{29}$ And if default costs in turn decrease with the number of people that have already defaulted, future recessions could further ratchet up default rates.

This analysis can be extended in a number of ways. First, the authors are attempting to collect additional data to lengthen the sample period. Second, better predictors of default might be constructed. Evidently the credit risk scores did not fully predict the recent increase in default rates. Since variables other than the scores were also found to be significant in predicting default, the scores might not even be efficient predictors. Better predictors might improve credit risk management and lead to a more efficient allocation of credit. Further, the standard risk scores do not summarize the expected future profitability of accounts. "Profit scores" might be constructed

confound the risk and demand effects.

${ }^{29}$ Increased defaults raise the marginal costs of lending. If marginal revenues do not increase correspondingly, for instance if lenders are constrained in raising interest rates, then one would expect less lending in response. Credit card issuers have recently tightened lending standards, apparently in response to increased losses over our sample period. In conjunction with an ever improving economy, this might have helped recently stem the rise in the bankruptcy rate, but it remains high by historical standards [Moody's (1999)]. Also, there is an "inventory" issue that might put some downwards pressure on the bankruptcy rate in the future: most bankrupts file under Chapter 7, which does not allow them to file again for another six years. 
to combine default probabilities with expected future cash flows. Third, because the estimated demand effect represents an increase in the probability of default that is common across accounts, it would be interesting to examine its implications for portfolio diversification and securitization. Fourth, in a companion paper, Gross and Souleles (2001), the authors investigate more generally how people use their credit cards, including how they respond to changes in credit supply. Understanding why people accumulate large quantities of debt in the first place should shed additional light on why some people default. ${ }^{30}$

\footnotetext{
30 Jappelli, Pischke, and Souleles (1998) document the consumption-smoothing benefits of credit-cards and other forms of consumer credit. Gross (1997) performs an analogous exercise for firms' investment.
} 


\section{References}

Ausubel, L., 1997, "Credit Card Defaults, Credit Card Profits, and Bankruptcy," The American Bankruptcy Law Journal, 99(5), 249-270.

Ausubel, L., 1999, “Adverse Selection in the Credit Card Market," working paper, University of Maryland.

Domowitz, I., and R. Sartain, 1999, "Determinants of the Consumer Bankruptcy Decision," Journal of Finance, 54, 403-420.

Fay, S., E. Hurst, and M. White, 1998, "The Bankruptcy Decision: Does Stigma Matter?" working paper, University of Michigan.

Federal Reserve Bank of Cleveland, 1998, Economic Trends, July.

Federal Reserve System, Board of Governors, 1999, Flow of Funds Accounts of the United States, Second Quarter.

Greene, W, 1991, Econometric Analysis, Macmillan, New York.

Gross, D., and N. Souleles, 2001, "Do Liquidity Constraints and Interest Rates Matter for Consumer Behavior? Evidence from Credit Card Data," forthcoming in The Quarterly Journal of Economics.

Gross, D., 1997, "The Investment and Financing Decisions of Liquidity Constrained Firms," working paper, University of Chicago.

Hoynes, H., 1999, "Local Labor Markets and Welfare Spells: Do Demand Conditions Matter?" working paper, University of California, Berkeley.

Hynes, R., 1998, Three Essays on Consumer Bankruptcy and Exemptions, manuscript, University of Pennsylvania.

Jappelli, T., S. Pischke, and N. Souleles, 1998, "Testing for Liquidity Constraints in Euler 
Equations with Complementary Data Sources," The Review of Economics and Statistics, $80,251-262$.

Moody's, 1997, "Increased Bankruptcies are Not Proof of Consumer Debt Crisis," Economic Commentary, April.

Moody's, 1999, "Market Optimism Sets Tone for 1999 U.S. Credit Card Asset Backed Securitizations," February.

Moss, D., and G. Johnson, 1998, "The Rise of Consumer Bankruptcy: Evolution, Revolution, or Both?" working paper, Harvard Business School.

Musto, D., 2000, “The Effect of Personal Bankruptcy on Credit Access: Evidence from a Panel Database of Credit Reports,” working paper, University of Pennsylvania.

New York Times, 1998, “The Sky is Becoming the Only Limit for Credit Card Users,” August 9. Saunders, A., 1999, Credit Risk Management, John Wiley \& Sons, New York.

Shumway, T., 1998, "Forecasting Bankruptcy More Accurately: A Simple Hazard Model," working paper, University of Michigan.

Weller, J., 1997, “Time for the Great Train Wreck?” Business Credit 99(5), 6-10.

White, M., 1997, “Why Don't More Households File for Bankruptcy?" working paper, University of Michigan. 


\section{Table 1}

\section{Summary Statistics}

\begin{tabular}{lccc} 
variable & mean & $\begin{array}{c}25^{\text {th }} \\
\text { percentile }\end{array}$ & $\begin{array}{c}75^{\text {th }} \\
\text { percentile }\end{array}$ \\
\hline age & 20.5 & 11 & 26 \\
utilization & 0.45 & 0.04 & 0.85 \\
payments & 0.045 & 0.000 & 0.035 \\
purchases & 0.037 & 0.000 & 0.034 \\
line & 4914 & 3000 & 6000 \\
internal_score & 714 & 681 & 750 \\
external_score & 699 & 658 & 746 \\
unemployment & 0.055 & 0.049 & 0.063 \\
no_insurance & 0.149 & 0.110 & 0.184 \\
house_prices & 93.9 & 81.7 & 93.2 \\
average_income & 15.6 & 14.1 & 16.8 \\
poverty_rate & 0.133 & 0.106 & 0.165 \\
BK & 0.020 & 0 & 0 \\
DEL & 0.082 & 0 & 0 \\
\hline
\end{tabular}

This table provides summary statistics for some of the key variables in the analysis. age represents a credit card account's age in months, line its credit limit. The utilization rate is balances divided by the line. payments and purchases are also normalized by the line. internal_score and external_score are the credit risk scores from the issuer and credit bureau. unemployment, average_income, and poverty_rate are the unemployment rate, per capita income (in thousands of $\$$ ), and poverty rate in the state of residence; no_insure is the fraction of people in the state without health insurance; and house_prices is the median real new house price in the census region (in thousands of \$). BK is an indicator for bankruptcy, DEL for three-cycle delinquency. Apart from BK and DEL, the statistics refer to the first month of the sample period. The reported statistics for BK and DEL measure the probability of ever going bankrupt or delinquent at any point in the sample period. These statistics cover both the bankruptcy and delinquency samples (3929 bankrupt and 13872 delinquent accounts, plus a control group of 9821 non-defaulting accounts), and are weighted to be representative. 
Table 2

Dynamic Probit Models of Bankruptcy

(1)

baseline specification
(2)

interact with age
(3)

update credit line

\begin{tabular}{|c|c|c|c|c|c|c|c|c|c|}
\hline & coef. & s.e. & p-val & coef. & s.e. & p-val & coef. & s.e. & p-val \\
\hline quarter2 & 0.136 & 0.024 & 0.000 & 0.148 & 0.025 & 0.000 & 0.136 & 0.024 & 0.000 \\
\hline quarter3 & 0.168 & 0.025 & 0.000 & 0.184 & 0.026 & 0.000 & 0.170 & 0.025 & 0.000 \\
\hline quarter4 & 0.237 & 0.026 & 0.000 & 0.258 & 0.028 & 0.000 & 0.240 & 0.026 & 0.000 \\
\hline quarter5 & 0.255 & 0.029 & 0.000 & 0.271 & 0.030 & 0.000 & 0.257 & 0.029 & 0.000 \\
\hline quarter6 & 0.286 & 0.030 & 0.000 & 0.298 & 0.031 & 0.000 & 0.291 & 0.030 & 0.000 \\
\hline quarter7 & 0.334 & 0.031 & 0.000 & 0.343 & 0.032 & 0.000 & 0.344 & 0.032 & 0.000 \\
\hline quarter8 & 0.388 & 0.033 & 0.000 & 0.394 & 0.033 & 0.000 & 0.401 & 0.033 & 0.000 \\
\hline age & 0.015 & 0.024 & 0.550 & -0.230 & 0.053 & 0.000 & 0.014 & 0.024 & 0.556 \\
\hline $\mathrm{age}^{2}$ & -0.028 & 0.144 & 0.846 & 0.179 & 0.163 & 0.271 & -0.022 & 0.144 & 0.880 \\
\hline age $^{3}$ & 0.009 & 0.382 & 0.982 & 0.152 & 0.407 & 0.709 & -0.019 & 0.382 & 0.961 \\
\hline age $^{4}$ & 0.010 & 0.462 & 0.983 & -0.119 & 0.490 & 0.808 & 0.054 & 0.462 & 0.907 \\
\hline $\operatorname{age}^{5}$ & -0.001 & 0.206 & 0.995 & 0.040 & 0.218 & 0.853 & -0.025 & 0.206 & 0.904 \\
\hline utilization2 & 0.067 & 0.038 & 0.079 & 0.011 & 0.046 & 0.806 & 0.076 & 0.038 & 0.046 \\
\hline utilization3 & 0.282 & 0.040 & 0.000 & 0.106 & 0.069 & 0.125 & 0.291 & 0.040 & 0.000 \\
\hline utilization4 & 0.277 & 0.045 & 0.000 & 0.069 & 0.077 & 0.370 & 0.288 & 0.045 & 0.000 \\
\hline utilization5 & 0.363 & 0.042 & 0.000 & 0.139 & 0.080 & 0.084 & 0.370 & 0.042 & 0.000 \\
\hline utilization6 & 0.506 & 0.040 & 0.000 & 0.271 & 0.087 & 0.002 & 0.512 & 0.040 & 0.000 \\
\hline utilization7 & 0.544 & 0.050 & 0.000 & 0.316 & 0.100 & 0.002 & 0.543 & 0.050 & 0.000 \\
\hline payments & -0.956 & 0.176 & 0.000 & -6.928 & 1.651 & 0.000 & -0.970 & 0.179 & 0.000 \\
\hline purchases & 0.156 & 0.093 & 0.091 & 1.060 & 0.375 & 0.005 & 0.143 & 0.092 & 0.121 \\
\hline line & $-1.3 \mathrm{E}-6$ & $3.4 \mathrm{E}-6$ & 0.695 & $5.0 \mathrm{E}-6$ & $1.3 E-5$ & 0.699 & $-1.3 E-5$ & $3.0 \mathrm{E}-6$ & 0.000 \\
\hline internal_score & -0.029 & 0.005 & 0.000 & -0.030 & 0.006 & 0.000 & -0.029 & 0.006 & 0.000 \\
\hline internal_score ${ }^{2}$ & 0.018 & 0.004 & 0.000 & 0.014 & 0.004 & 0.001 & 0.019 & 0.004 & 0.000 \\
\hline external_score & 0.019 & 0.003 & 0.000 & 0.019 & 0.003 & 0.000 & 0.019 & 0.003 & 0.000 \\
\hline external score ${ }^{2}$ & -0.017 & 0.002 & 0.000 & -0.016 & 0.002 & 0.000 & -0.017 & 0.002 & 0.000 \\
\hline unemployment & 5.256 & 1.109 & 0.000 & 5.006 & 1.116 & 0.000 & 5.466 & 1.113 & 0.000 \\
\hline no_insurance & 0.452 & 0.280 & 0.107 & 0.477 & 0.285 & 0.094 & 0.479 & 0.284 & 0.092 \\
\hline house_prices & -0.002 & 0.001 & 0.037 & -0.002 & 0.001 & 0.043 & -0.002 & 0.001 & 0.048 \\
\hline average_income & -0.001 & 0.007 & 0.834 & -0.001 & 0.007 & 0.863 & -0.001 & 0.007 & 0.913 \\
\hline poverty_rate & -0.776 & 0.469 & 0.098 & -0.827 & 0.481 & 0.086 & -0.821 & 0.477 & 0.085 \\
\hline \# of obs & & 218025 & & & 218025 & & & 218025 & \\
\hline log likelihood & & -1786.9 & & & -1779.9 & & & -1785.6 & \\
\hline pseudo R2 & & 0.126 & & & 0.129 & & & 0.127 & \\
\hline
\end{tabular}

This table shows the results of probit models of bankruptcy (BK) using monthly credit-card account panel data from July 1995 through June 1997. The independent variables control for time effects, account age, measures of account risk, and local economic conditions. quarter 2 to quarter 8 are dummy variables for the calendar quarter. age to $a g e^{5}$ represent a fifth-order polynomial in account age. utilization 2 to utilization 7 are dummy variables for successively higher utilization rates. line is the credit limit, and payments and purchases are normalized by the line. internal_score and external_score are the credit risk scores. unemployment, average_income, and poverty_rate are the unemployment rate, per capita income, and poverty rate in the state of residence, no_insure the fraction of people without health insurance, and house_prices the median real new house price in the region. Coefficients on dummy 
variables for the issuer are not shown. Standard errors are corrected for heteroskedasticity and dependence within accounts. The number of observations is the number of account-months. $a e^{n}=a g e^{n-}$ ${ }^{1 *}$ age/100. external_score ${ }^{2}=$ external_score* $* x t e r n a l \_s c o r e / 1000$. internal_score ${ }^{2}=$ internal_score* internal_score $/ 1000$.

In the baseline specification in column (1) the risk controls $\boldsymbol{r i s}_{i, 0}$ (utilization, payments, purchases, line, and the scores) are all taken from month 0 , June 1995. Column (2) interacts the risk controls with a quadratic polynomial in account age. Only the coefficients on the primary, non-interacted variables are shown. Column (3) uses the updated credit limit (once lagged). Column (4) updates the risk controls using ris $\boldsymbol{k}_{i, t}$ 6. Column (5) adds dummy variables for the cardholder's state, whose coefficients are not shown. staterate in column (6) is the aggregate bankruptcy rate in the state, averaged over the previous two calendar quarters. 
Table 2:

Dynamic Probit Models of Bankruptcy (ctd)

(4)

update risk controls
(5)

state dummies
(6) state bankruptcy rate

\begin{tabular}{|c|c|c|c|c|c|c|c|c|c|}
\hline & coef. & s.e. & p-val & coef. & s.e. & p-val & coef. & s.e. & p-val \\
\hline quarter2 & & & & 0.144 & 0.024 & 0.000 & 0.126 & 0.024 & 0.000 \\
\hline quarter3 & & & & 0.186 & 0.028 & 0.000 & 0.158 & 0.025 & 0.000 \\
\hline quarter4 & 0.082 & 0.021 & 0.000 & 0.258 & 0.031 & 0.000 & 0.214 & 0.027 & 0.000 \\
\hline quarter5 & 0.054 & 0.025 & 0.030 & 0.286 & 0.036 & 0.000 & 0.208 & 0.030 & 0.000 \\
\hline quarter6 & 0.085 & 0.027 & 0.001 & 0.320 & 0.037 & 0.000 & 0.230 & 0.032 & 0.000 \\
\hline quarter7 & 0.120 & 0.028 & 0.000 & 0.380 & 0.047 & 0.000 & 0.277 & 0.033 & 0.000 \\
\hline quarter8 & 0.165 & 0.030 & 0.000 & 0.445 & 0.056 & 0.000 & 0.323 & 0.035 & 0.000 \\
\hline age & -0.067 & 0.041 & 0.101 & 0.010 & 0.025 & 0.689 & 0.017 & 0.025 & 0.490 \\
\hline $\mathrm{age}^{2}$ & 0.361 & 0.226 & 0.111 & -0.002 & 0.145 & 0.990 & -0.040 & 0.145 & 0.782 \\
\hline age $^{3}$ & -0.836 & 0.574 & 0.145 & -0.059 & 0.386 & 0.878 & 0.029 & 0.385 & 0.939 \\
\hline$a^{4} e^{4}$ & 0.872 & 0.668 & 0.192 & 0.092 & 0.468 & 0.845 & -0.001 & 0.466 & 0.998 \\
\hline age $^{5}$ & -0.336 & 0.290 & 0.246 & -0.038 & 0.209 & 0.856 & -0.002 & 0.208 & 0.992 \\
\hline utilization2 & 0.264 & 0.057 & 0.000 & 0.063 & 0.039 & 0.104 & 0.067 & 0.038 & 0.079 \\
\hline utilization3 & 0.453 & 0.060 & 0.000 & 0.278 & 0.040 & 0.000 & 0.282 & 0.040 & 0.000 \\
\hline utilization4 & 0.571 & 0.063 & 0.000 & 0.269 & 0.046 & 0.000 & 0.277 & 0.045 & 0.000 \\
\hline utilization5 & 0.625 & 0.061 & 0.000 & 0.360 & 0.043 & 0.000 & 0.363 & 0.042 & 0.000 \\
\hline utilization6 & 0.779 & 0.059 & 0.000 & 0.501 & 0.040 & 0.000 & 0.505 & 0.040 & 0.000 \\
\hline utilization7 & 0.865 & 0.064 & 0.000 & 0.540 & 0.050 & 0.000 & 0.542 & 0.050 & 0.000 \\
\hline payments & -1.959 & 0.449 & 0.000 & -0.991 & 0.183 & 0.000 & -0.975 & 0.178 & 0.000 \\
\hline purchases & 0.272 & 0.064 & 0.000 & 0.185 & 0.092 & 0.044 & 0.158 & 0.092 & 0.086 \\
\hline line & $7.2 \mathrm{E}-6$ & 3.3E-6 & 0.028 & $-4.3 \mathrm{E}-6$ & $3.5 \mathrm{E}-6$ & 0.212 & $-2.5 \mathrm{E}-6$ & $3.4 \mathrm{E}-6$ & 0.461 \\
\hline internal score & -0.040 & 0.005 & 0.000 & -0.030 & 0.005 & 0.000 & -0.028 & 0.005 & 0.000 \\
\hline internal_score ${ }^{2}$ & 0.026 & 0.004 & 0.000 & 0.019 & 0.004 & 0.000 & 0.018 & 0.004 & 0.000 \\
\hline external_score & 0.017 & 0.002 & 0.000 & 0.019 & 0.003 & 0.000 & 0.019 & 0.003 & 0.000 \\
\hline external_score ${ }^{2}$ & -0.015 & 0.002 & 0.000 & -0.017 & 0.002 & 0.000 & -0.017 & 0.002 & 0.000 \\
\hline unemployment & 5.679 & 1.278 & 0.000 & 0.367 & 2.166 & 0.866 & 3.227 & 1.170 & 0.006 \\
\hline no_insurance & 0.567 & 0.311 & 0.068 & -1.973 & 1.078 & 0.067 & 0.177 & 0.282 & 0.530 \\
\hline house_prices & -0.002 & 0.001 & 0.076 & -0.007 & 0.006 & 0.182 & 0.000 & 0.001 & 0.795 \\
\hline average income & 0.001 & 0.007 & 0.848 & -0.059 & 0.073 & 0.420 & -0.005 & 0.007 & 0.408 \\
\hline poverty_rate & -0.651 & 0.522 & 0.212 & 1.148 & 1.038 & 0.268 & -0.237 & 0.466 & 0.612 \\
\hline staterate & & & & & & & 807 & 144 & 0.000 \\
\hline staterate $^{2}$ & & & & & & & $-2.9 E+5$ & $6.0 \mathrm{E}+4$ & 0.000 \\
\hline \# of obs & & 152885 & & & 218025 & & & 218025 & \\
\hline log likelihood & & -1328.1 & & & -1778.3 & & & -1783.8 & \\
\hline pseudo R2 & & 0.176 & & & 0.130 & & & 0.127 & \\
\hline
\end{tabular}




\section{Table 3}

\section{Marginal Effects for Bankruptcy}

\begin{tabular}{|c|c|c|c|c|c|c|}
\hline \multirow[b]{3}{*}{$\begin{array}{l}\text { demand }_{t} \\
\text { quarter } 1\end{array}$} & \multicolumn{2}{|c|}{$\begin{array}{l}\text { (1) baseline } \\
\text { specification }\end{array}$} & \multicolumn{2}{|c|}{$\begin{array}{l}\text { (2) interact } \\
\text { with age }\end{array}$} & \multicolumn{2}{|c|}{$\begin{array}{l}\text { (3) update } \\
\text { credit line }\end{array}$} \\
\hline & marginal & s.e. & marginal & s.e. & marginal & s.e. \\
\hline & $0.000 \%$ & & $0.000 \%$ & & $0.000 \%$ & \\
\hline quarter2 & $0.013 \%$ & $0.002 \%$ & $0.010 \%$ & $0.002 \%$ & $0.013 \%$ & $0.002 \%$ \\
\hline quarter3 & $0.017 \%$ & $0.003 \%$ & $0.013 \%$ & $0.002 \%$ & $0.018 \%$ & $0.003 \%$ \\
\hline quarter4 & $0.027 \%$ & $0.004 \%$ & $0.022 \%$ & $0.003 \%$ & $0.028 \%$ & $0.004 \%$ \\
\hline quarter5 & $0.030 \%$ & $0.004 \%$ & $0.023 \%$ & $0.004 \%$ & $0.032 \%$ & $0.005 \%$ \\
\hline quarter6 & $0.036 \%$ & $0.005 \%$ & $0.027 \%$ & $0.004 \%$ & $0.038 \%$ & $0.005 \%$ \\
\hline quarter7 & $0.046 \%$ & $0.006 \%$ & $0.034 \%$ & $0.005 \%$ & $0.050 \%$ & $0.007 \%$ \\
\hline quarter8 & $0.060 \%$ & $0.008 \%$ & $0.044 \%$ & $0.006 \%$ & $0.065 \%$ & $0.008 \%$ \\
\hline riskcomp $\mathrm{t}_{\mathrm{t}}$ & & & & & & \\
\hline $\begin{array}{l}\text { quarter1 } \\
\text { quarter2 }\end{array}$ & $0.000 \%$ & & & & $0.000 \%$ & \\
\hline quarter2 & $0.001 \%$ & $0.000 \%$ & $0.002 \%$ & $0.000 \%$ & $0.000 \%$ & $\begin{array}{l}0.000 \% \\
0.001 \%\end{array}$ \\
\hline $\begin{array}{l}\text { quarter3 } \\
\text { quarter4 }\end{array}$ & $\begin{array}{l}0.001 \% \\
0.001 \%\end{array}$ & $0.001 \%$ & $\begin{array}{l}0.003 \% \\
0.004 \%\end{array}$ & $0.001 \%$ & $\begin{array}{l}0.001 \% \\
0.000 \%\end{array}$ & $\begin{array}{l}0.001 \% \\
0.001 \%\end{array}$ \\
\hline quarter5 & $-0.006 \%$ & $0.001 \%$ & $-0.001 \%$ & $0.001 \%$ & $-0.007 \%$ & $0.001 \%$ \\
\hline quarter6 & $-0.006 \%$ & $0.001 \%$ & $-0.001 \%$ & $0.001 \%$ & $-0.007 \%$ & $0.001 \%$ \\
\hline quarter7 & $-0.006 \%$ & $0.001 \%$ & $-0.001 \%$ & $0.001 \%$ & $-0.008 \%$ & $0.001 \%$ \\
\hline quarter8 & $-0.007 \%$ & $0.001 \%$ & $-0.001 \%$ & $0.001 \%$ & $-0.009 \%$ & $0.001 \%$ \\
\hline
\end{tabular}

\begin{tabular}{|c|c|c|c|c|c|c|}
\hline \multirow{2}{*}{ demand $_{t}$} & \multicolumn{2}{|c|}{$\begin{array}{l}\text { (4) update risk } \\
\text { controls }\end{array}$} & \multicolumn{2}{|c|}{$\begin{array}{l}\text { (5) state } \\
\text { dummies }\end{array}$} & \multicolumn{2}{|c|}{$\begin{array}{c}\text { (6) state } \\
\text { bankruptcy rate }\end{array}$} \\
\hline & marginal & & marginal & s.e. & marginal & s.e. \\
\hline quarter1 & & & $0.000 \%$ & & $0.000 \%$ & \\
\hline quarter2 & & & $0.013 \%$ & $0.002 \%$ & $0.011 \%$ & $0.002 \%$ \\
\hline quarter3 & $0.000 \%$ & & $0.018 \%$ & $0.003 \%$ & $0.015 \%$ & $0.003 \%$ \\
\hline quarter4 & $0.008 \%$ & $0.002 \%$ & $0.029 \%$ & $0.005 \%$ & $0.023 \%$ & $0.003 \%$ \\
\hline quarter5 & $0.005 \%$ & $0.002 \%$ & $0.034 \%$ & $0.006 \%$ & $0.022 \%$ & $0.004 \%$ \\
\hline quarter6 & $0.008 \%$ & $0.003 \%$ & $0.041 \%$ & $0.007 \%$ & $0.025 \%$ & $0.004 \%$ \\
\hline quarter7 & $0.012 \%$ & $0.003 \%$ & $0.055 \%$ & $0.011 \%$ & $0.033 \%$ & $0.005 \%$ \\
\hline quarter8 & $0.018 \%$ & $0.004 \%$ & $0.073 \%$ & $0.017 \%$ & $0.043 \%$ & $0.007 \%$ \\
\hline riskcomp & & & & & & \\
\hline quarter1 & & & $0.000 \%$ & & $0.000 \%$ & \\
\hline quarter2 & & & $0.000 \%$ & $0.001 \%$ & $0.001 \%$ & $0.001 \%$ \\
\hline quarter3 & $0.000 \%$ & & $0.000 \%$ & $0.001 \%$ & $0.002 \%$ & $0.001 \%$ \\
\hline quarter4 & $-0.002 \%$ & $0.000 \%$ & $0.000 \%$ & $0.001 \%$ & $0.003 \%$ & $0.001 \%$ \\
\hline quarter5 & $-0.008 \%$ & $0.001 \%$ & $-0.007 \%$ & $0.001 \%$ & $-0.003 \%$ & $0.001 \%$ \\
\hline quarter6 & $-0.007 \%$ & $0.001 \%$ & $-0.007 \%$ & $0.002 \%$ & $-0.003 \%$ & $0.001 \%$ \\
\hline quarter7 & $-0.006 \%$ & $0.001 \%$ & $-0.008 \%$ & $0.002 \%$ & $-0.003 \%$ & $0.001 \%$ \\
\hline quarter8 & $-0.006 \%$ & $0.001 \%$ & $-0.009 \%$ & $0.002 \%$ & $-0.003 \%$ & $0.002 \%$ \\
\hline
\end{tabular}

Each column reports the marginal effects for the probit models in the corresponding column in Table 2,

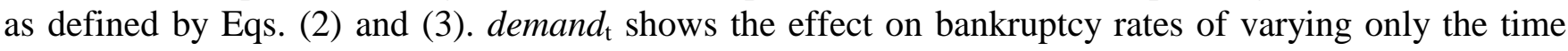

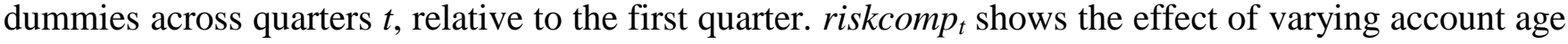
and the economic control variables across their cross-sectional averages in different quarters. The units are in percentage points per month. 


\section{Table 4}

\section{Dynamic Probit Models of Delinquency}

(1)

baseline specification
(2)

interact with age
(3) update credit line

\begin{tabular}{|c|c|c|c|c|c|c|c|c|c|}
\hline & coef. & s.e. & p-val & coef. & s.e. & $\mathrm{p}$-val & coef. & s.e. & p-val \\
\hline quarter2 & 0.221 & 0.014 & 0.000 & 0.237 & 0.014 & 0.000 & 0.222 & 0.014 & 0.000 \\
\hline quarter3 & 0.257 & 0.015 & 0.000 & 0.276 & 0.016 & 0.000 & 0.261 & 0.015 & 0.000 \\
\hline quarter4 & 0.255 & 0.017 & 0.000 & 0.275 & 0.018 & 0.000 & 0.263 & 0.017 & 0.000 \\
\hline quarter5 & 0.339 & 0.020 & 0.000 & 0.354 & 0.020 & 0.000 & 0.350 & 0.020 & 0.000 \\
\hline quarter6 & 0.387 & 0.021 & 0.000 & 0.398 & 0.022 & 0.000 & 0.407 & 0.021 & 0.000 \\
\hline quarter7 & 0.391 & 0.023 & 0.000 & 0.398 & 0.023 & 0.000 & 0.422 & 0.023 & 0.000 \\
\hline quarter8 & 0.368 & 0.024 & 0.000 & 0.373 & 0.025 & 0.000 & 0.406 & 0.025 & 0.000 \\
\hline age & 0.060 & 0.016 & 0.000 & -0.115 & 0.039 & 0.003 & 0.062 & 0.016 & 0.000 \\
\hline age $^{2}$ & -0.347 & 0.099 & 0.000 & -0.147 & 0.113 & 0.193 & -0.357 & 0.099 & 0.000 \\
\hline age $^{3}$ & 0.871 & 0.273 & 0.001 & 0.789 & 0.277 & 0.004 & 0.882 & 0.274 & 0.001 \\
\hline age $^{4}$ & -0.999 & 0.340 & 0.003 & -0.864 & 0.343 & 0.012 & -0.998 & 0.341 & 0.003 \\
\hline age $^{5}$ & 0.428 & 0.155 & 0.006 & 0.360 & 0.156 & 0.021 & 0.422 & 0.156 & 0.007 \\
\hline utilization2 & 0.014 & 0.022 & 0.539 & 0.035 & 0.027 & 0.202 & 0.030 & 0.022 & 0.173 \\
\hline utilization3 & 0.036 & 0.026 & 0.172 & 0.052 & 0.044 & 0.238 & 0.051 & 0.026 & 0.051 \\
\hline utilization4 & 0.025 & 0.031 & 0.430 & 0.024 & 0.052 & 0.643 & 0.043 & 0.032 & 0.178 \\
\hline utilization5 & 0.042 & 0.029 & 0.152 & 0.024 & 0.055 & 0.659 & 0.056 & 0.029 & 0.057 \\
\hline utilization6 & 0.130 & 0.027 & 0.000 & 0.093 & 0.061 & 0.130 & 0.142 & 0.027 & 0.000 \\
\hline utilization7 & 0.179 & 0.038 & 0.000 & 0.136 & 0.074 & 0.066 & 0.183 & 0.038 & 0.000 \\
\hline payments & -0.943 & 0.096 & 0.000 & -4.007 & 0.666 & 0.000 & -0.950 & 0.098 & 0.000 \\
\hline purchases & 0.523 & 0.079 & 0.000 & 1.044 & 0.243 & 0.000 & 0.512 & 0.078 & 0.000 \\
\hline line & $-2.2 E-5$ & $3.0 \mathrm{E}-6$ & 0.000 & $-4.3 E-5$ & $1.0 \mathrm{E}-5$ & 0.000 & $-3.3 E-5$ & $2.6 \mathrm{E}-6$ & 0.000 \\
\hline internal score & -0.035 & 0.004 & 0.000 & -0.032 & 0.004 & 0.000 & -0.036 & 0.004 & 0.000 \\
\hline internal_score ${ }^{2}$ & 0.021 & 0.003 & 0.000 & 0.015 & 0.003 & 0.000 & 0.022 & 0.003 & 0.000 \\
\hline external_score & 0.002 & 0.002 & 0.325 & 0.002 & 0.002 & 0.311 & 0.002 & 0.002 & 0.479 \\
\hline external_score ${ }^{2}$ & -0.004 & 0.002 & 0.015 & -0.004 & 0.002 & 0.017 & -0.003 & 0.002 & 0.041 \\
\hline unemployment & 0.545 & 0.923 & 0.555 & 0.337 & 0.928 & 0.717 & 0.723 & 0.930 & 0.437 \\
\hline no insurance & 0.662 & 0.259 & 0.011 & 0.691 & 0.262 & 0.008 & 0.685 & 0.265 & 0.010 \\
\hline house_prices & 0.000 & 0.001 & 0.853 & 0.000 & 0.001 & 0.760 & 0.000 & 0.001 & 0.816 \\
\hline average income & 0.003 & 0.006 & 0.592 & 0.003 & 0.007 & 0.655 & 0.004 & 0.007 & 0.528 \\
\hline poverty_rate & -0.216 & 0.430 & 0.615 & -0.276 & 0.440 & 0.530 & -0.242 & 0.440 & 0.582 \\
\hline \# of obs & & 337558 & & & 337558 & & & 337558 & \\
\hline log likelihood & & -7466.7 & & & -7448.1 & & & -7445.9 & \\
\hline pseudo R2 & & 0.139 & & & 0.141 & & & 0.141 & \\
\hline
\end{tabular}

This table shows the results of probit models of delinquency (DEL) using monthly credit-card account panel data from July 1995 through June 1997. The independent variables control for time effects, account age, measures of account risk, and local economic conditions. quarter 2 to quarter 8 are dummy variables for the calendar quarter. age to $a g e^{5}$ represent a fifth-order polynomial in account age. utilization 2 to utilization 7 are dummy variables for successively higher utilization rates. line is the credit limit, and payments and purchases are normalized by the line. internal_score and external_score are the credit risk scores. unemployment, average_income, and poverty_rate are the unemployment rate, per capita income, and poverty rate in the state of residence, no_insure the fraction of people without health 
insurance, and house_prices the median real new house price in the region. Coefficients on dummy variables for the issuer are not shown. Standard errors are corrected for heteroskedasticity and dependence within accounts. The number of observations is the number of account-months. age $e^{n}=a g e^{n-}$ ${ }^{1} * a g e / 100$. external_score ${ }^{2}=$ external_score ${ }^{*}$ external_score/1000. internal_score ${ }^{2}=$ internal_score $^{*}$ internal_score $/ 1000$.

In the baseline specification in column (1) the risk controls risk $_{i, 0}$ (utilization, payments, purchases, line, and the scores) are all taken from month 0 , June 1995. Column (2) interacts the risk controls with a quadratic polynomial in account age. Only the coefficients on the primary, non-interacted variables are shown. Column (3) uses the updated credit limit (once lagged). Column (4) updates the risk controls using risk $\boldsymbol{k}_{i, t}$ 6. Column (5) adds dummy variables for the cardholder's state, whose coefficients are not shown. 


\section{Table 4}

\section{Dynamic Probit Models of Delinquency (ctd)}

(4)

update risk controls

\begin{tabular}{|c|c|c|c|c|c|c|}
\hline & coef. & s.e. & $p$-val & coef. & s.e. & $p$-val \\
\hline quarter2 & & & & 0.220 & 0.014 & 0.000 \\
\hline quarter3 & & & & 0.249 & 0.017 & 0.000 \\
\hline quarter4 & -0.009 & 0.013 & 0.474 & 0.242 & 0.020 & 0.000 \\
\hline quarter5 & 0.042 & 0.016 & 0.008 & 0.326 & 0.023 & 0.000 \\
\hline quarter6 & 0.060 & 0.017 & 0.000 & 0.373 & 0.025 & 0.000 \\
\hline quarter7 & 0.059 & 0.019 & 0.002 & 0.362 & 0.032 & 0.000 \\
\hline quarter8 & 0.034 & 0.021 & 0.112 & 0.327 & 0.037 & 0.000 \\
\hline age & -0.020 & 0.028 & 0.458 & 0.052 & 0.016 & 0.001 \\
\hline $\operatorname{age}^{2}$ & 0.070 & 0.158 & 0.659 & -0.307 & 0.099 & 0.002 \\
\hline age $^{3}$ & -0.116 & 0.408 & 0.777 & 0.776 & 0.273 & 0.005 \\
\hline age $^{4}$ & 0.086 & 0.484 & 0.859 & -0.896 & 0.340 & 0.008 \\
\hline age $^{5}$ & -0.021 & 0.213 & 0.923 & 0.387 & 0.155 & 0.013 \\
\hline utilization2 & 0.020 & 0.022 & 0.377 & 0.011 & 0.022 & 0.619 \\
\hline utilization3 & 0.034 & 0.026 & 0.193 & 0.032 & 0.026 & 0.216 \\
\hline utilization4 & 0.080 & 0.030 & 0.007 & 0.020 & 0.032 & 0.522 \\
\hline utilization5 & 0.098 & 0.028 & 0.000 & 0.038 & 0.029 & 0.197 \\
\hline utilization6 & 0.183 & 0.026 & 0.000 & 0.126 & 0.027 & 0.000 \\
\hline utilization7 & 0.280 & 0.031 & 0.000 & 0.184 & 0.037 & 0.000 \\
\hline payments & -1.017 & 0.097 & 0.000 & -0.940 & 0.095 & 0.000 \\
\hline purchases & 0.470 & 0.041 & 0.000 & 0.542 & 0.077 & 0.000 \\
\hline line & $-1.5 \mathrm{E}-5$ & 2.7E-6 & 0.000 & $-2.3 E-5$ & $3.0 \mathrm{E}-6$ & 0.000 \\
\hline internal_score & -0.020 & 0.004 & 0.000 & -0.036 & 0.004 & 0.000 \\
\hline internal_score ${ }^{2}$ & 0.009 & 0.003 & 0.001 & 0.021 & 0.003 & 0.000 \\
\hline external_score & -0.001 & 0.002 & 0.594 & 0.002 & 0.002 & 0.280 \\
\hline external_score ${ }^{2}$ & -0.002 & 0.001 & 0.155 & -0.004 & 0.002 & 0.010 \\
\hline unemployment & -0.552 & 1.015 & 0.587 & -1.084 & 1.453 & 0.456 \\
\hline no_insurance & 0.486 & 0.260 & 0.061 & -0.396 & 0.699 & 0.571 \\
\hline house_prices & 0.000 & 0.001 & 0.732 & 0.002 & 0.004 & 0.669 \\
\hline average_income & 0.005 & 0.006 & 0.381 & 0.075 & 0.046 & 0.102 \\
\hline poverty_rate & 0.129 & 0.429 & 0.764 & 0.403 & 0.679 & 0.553 \\
\hline \# of obs & & 230215 & & & 337558 & \\
\hline log likelihood & & -5430.7 & & & -7448.4 & \\
\hline pseudo R2 & & 0.179 & & & 0.141 & \\
\hline
\end{tabular}

(5)

state dummies 


\section{Table 5}

\section{Marginal Effects for Delinquency}

\begin{tabular}{|c|c|c|c|c|c|c|}
\hline \multirow[b]{3}{*}{$\begin{array}{r}\text { demand }_{\mathrm{t}} \\
\text { quarter1 }\end{array}$} & \multicolumn{2}{|c|}{$\begin{array}{l}\text { (1) baseline } \\
\text { specification }\end{array}$} & \multicolumn{2}{|c|}{$\begin{array}{l}\text { (2) interact } \\
\text { with age }\end{array}$} & \multicolumn{2}{|c|}{$\begin{array}{l}\text { (3) update } \\
\text { credit line }\end{array}$} \\
\hline & marginal & s.e. & marginal & s.e. & marginal & s.e. \\
\hline & $0.000 \%$ & & $0.000 \%$ & & $0.000 \%$ & \\
\hline quarter2 & $0.091 \%$ & $0.006 \%$ & $0.080 \%$ & $0.006 \%$ & $0.096 \%$ & $0.006 \%$ \\
\hline quarter3 & $0.113 \%$ & $0.008 \%$ & $0.100 \%$ & $0.007 \%$ & $0.120 \%$ & $0.008 \%$ \\
\hline quarter4 & $0.111 \%$ & $0.009 \%$ & $0.100 \%$ & $0.008 \%$ & $0.122 \%$ & $0.009 \%$ \\
\hline quarter5 & $0.171 \%$ & $0.013 \%$ & $0.148 \%$ & $0.011 \%$ & $0.187 \%$ & $0.014 \%$ \\
\hline quarter6 & $0.211 \%$ & $0.016 \%$ & $0.179 \%$ & $0.014 \%$ & $0.239 \%$ & $0.018 \%$ \\
\hline quarter7 & $0.214 \%$ & $0.018 \%$ & $0.179 \%$ & $0.015 \%$ & $0.255 \%$ & $0.021 \%$ \\
\hline quarter8 & $0.194 \%$ & $0.018 \%$ & $0.160 \%$ & $0.015 \%$ & $0.238 \%$ & $0.022 \%$ \\
\hline riskcomp & & & & & & \\
\hline quarter1 & $0.000 \%$ & & $0.000 \%$ & & $0.000 \%$ & \\
\hline quarter2 & $0.000 \%$ & $0.001 \%$ & $0.004 \%$ & $0.001 \%$ & $-0.003 \%$ & $0.001 \%$ \\
\hline quarter3 & $-0.003 \%$ & $0.002 \%$ & $0.005 \%$ & $0.002 \%$ & $-0.008 \%$ & $0.002 \%$ \\
\hline quarter4 & $-0.007 \%$ & $0.002 \%$ & $0.005 \%$ & $0.002 \%$ & $-0.014 \%$ & $0.002 \%$ \\
\hline quarter5 & $-0.027 \%$ & $0.002 \%$ & $-0.010 \%$ & $0.003 \%$ & $-0.036 \%$ & $0.002 \%$ \\
\hline quarter6 & $-0.030 \%$ & $0.003 \%$ & $-0.011 \%$ & $0.003 \%$ & $-0.043 \%$ & $0.003 \%$ \\
\hline quarter7 & $-0.033 \%$ & $0.003 \%$ & $-0.012 \%$ & $0.003 \%$ & $-0.048 \%$ & $0.003 \%$ \\
\hline quarter8 & $-0.035 \%$ & $0.003 \%$ & $-0.013 \%$ & $0.003 \%$ & $-0.051 \%$ & $0.003 \%$ \\
\hline
\end{tabular}

\begin{tabular}{|c|c|c|c|c|}
\hline \multirow{2}{*}{ demand $_{\mathrm{t}}$} & \multicolumn{2}{|c|}{$\begin{array}{l}\text { (4) update risk } \\
\text { controls }\end{array}$} & \multicolumn{2}{|c|}{$\begin{array}{l}\text { (5) state } \\
\text { dummies }\end{array}$} \\
\hline & marginal & e. & marginal & s.e. \\
\hline quarter1 & & & $0.000 \%$ & \\
\hline quarter2 & & & $0.088 \%$ & $0.006 \%$ \\
\hline quarter3 & $0.000 \%$ & & $0.104 \%$ & $0.009 \%$ \\
\hline quarter4 & $-0.004 \%$ & $0.006 \%$ & $0.100 \%$ & $0.010 \%$ \\
\hline quarter5 & $0.020 \%$ & $0.008 \%$ & $0.156 \%$ & $0.016 \%$ \\
\hline quarter6 & $0.030 \%$ & $0.009 \%$ & $0.193 \%$ & $0.019 \%$ \\
\hline quarter7 & $0.029 \%$ & $0.010 \%$ & $0.183 \%$ & $0.025 \%$ \\
\hline quarter8 & $0.017 \%$ & $0.011 \%$ & $0.157 \%$ & $0.027 \%$ \\
\hline riskcomp $_{\mathrm{t}}$ & & & & \\
\hline quarter1 & & & $0.000 \%$ & \\
\hline quarter2 & & & $0.000 \%$ & $0.001 \%$ \\
\hline quarter3 & $0.000 \%$ & & $0.000 \%$ & $0.003 \%$ \\
\hline quarter4 & $-0.010 \%$ & $0.001 \%$ & $-0.003 \%$ & $0.004 \%$ \\
\hline quarter5 & $-0.036 \%$ & $0.003 \%$ & $-0.023 \%$ & $0.004 \%$ \\
\hline quarter6 & $-0.010 \%$ & $0.004 \%$ & $-0.026 \%$ & $0.004 \%$ \\
\hline quarter7 & $-0.019 \%$ & $0.005 \%$ & $-0.025 \%$ & $0.006 \%$ \\
\hline quarter8 & $-0.025 \%$ & $0.006 \%$ & $-0.025 \%$ & $0.007 \%$ \\
\hline
\end{tabular}

Each column reports the marginal effects for the probit models in the corresponding column in Table 4, as defined by Eqs. (2) and (3). demand $\mathrm{t}_{\mathrm{t}}$ shows the effect on delinquency rates of varying only the time dummies across quarters $t$, relative to the first quarter. riskcomp $p_{t}$ shows the effect of varying account age and the economic control variables across their cross-sectional averages in different quarters. The units are in percentage points per month. 


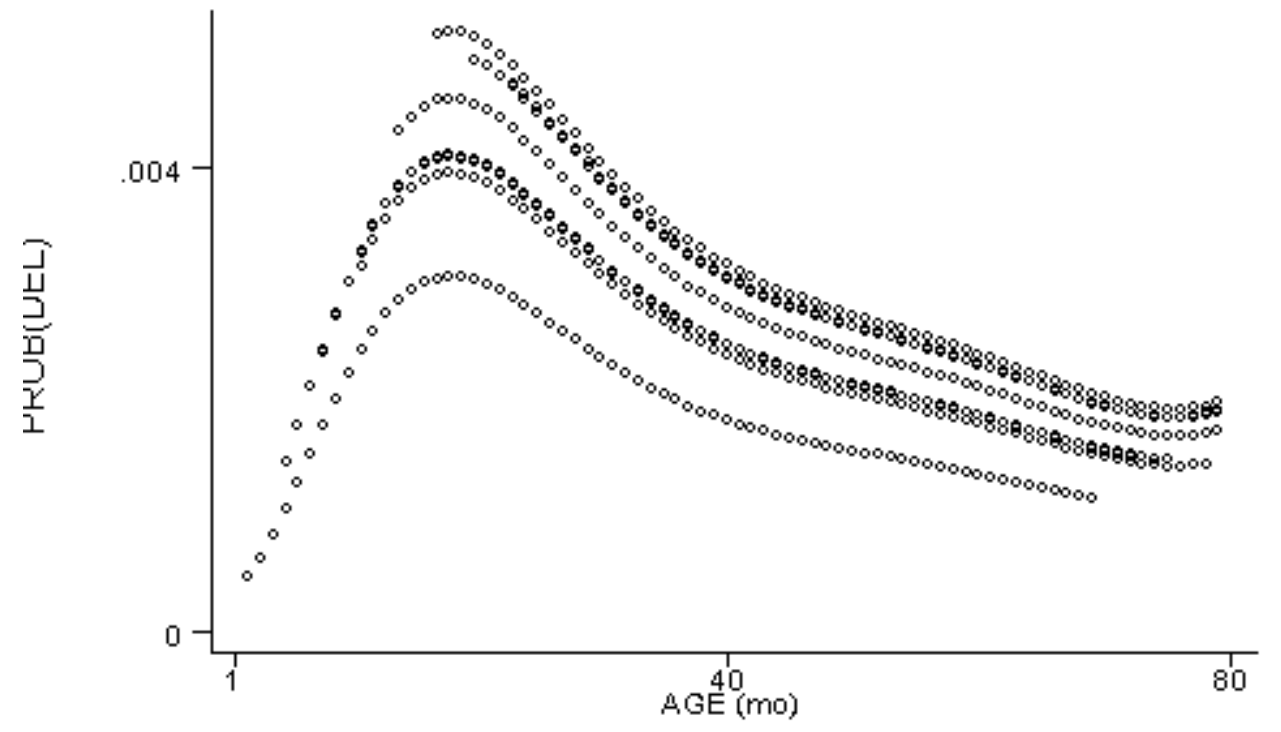

\section{Figure 1}

The effects of account age (in months) and time on the probability of delinquency

Each curve represents the hazard function for a different calendar quarter (from top to bottom, for a given age: sample quarters $6,8,7,5,2,3,4$, and 1). Each hazard function gives the average probability of an account going delinquent at the indicated age (months since booking), conditional on not having already defaulted. 


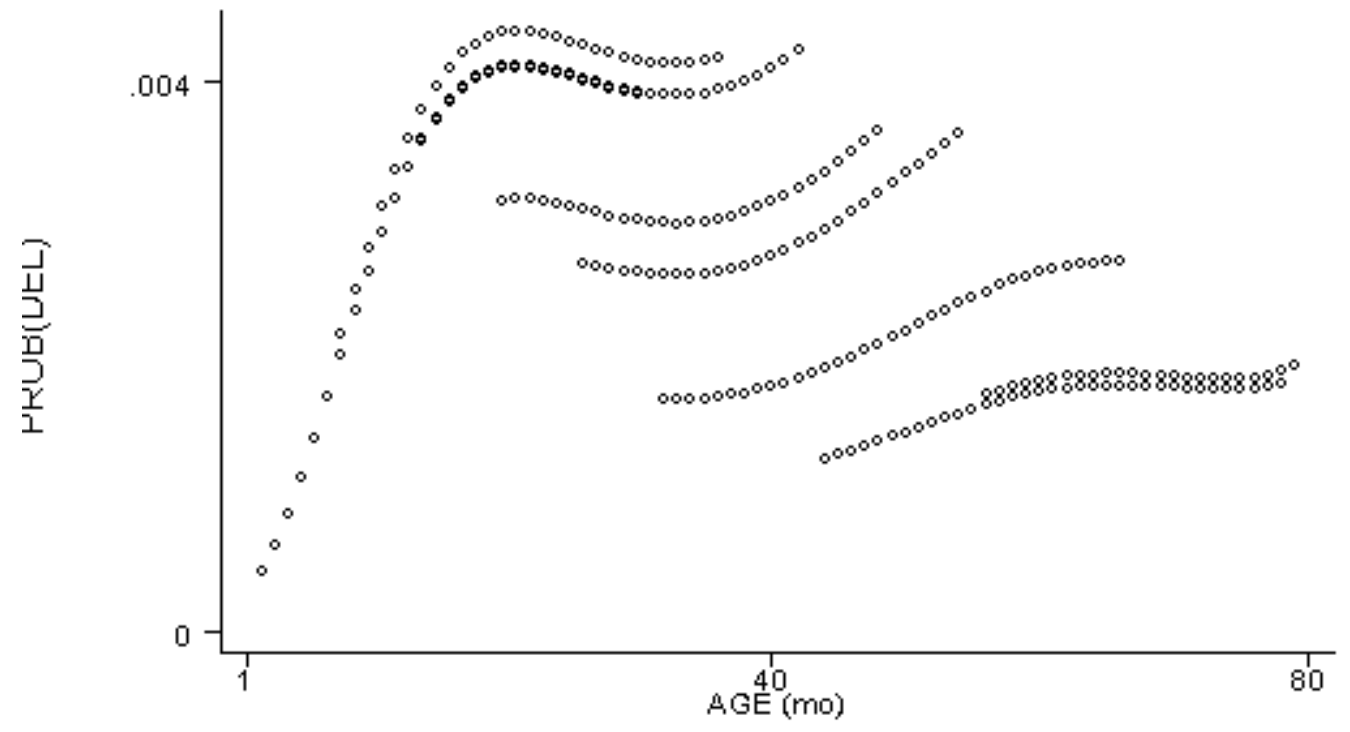

Figure 2

The effects of account age (in months) and cohort on the probability of delinquency

Each curve represents the hazard function for a different cohort of credit card accounts, over the period in which that cohort appears in the sample (from left to right: accounts booked in the first half of 1995, the second and first halves of 1994 and 1993, 1992, 1991, and 1990). Each hazard function gives the average probability of an account going delinquent at the indicated age (months since booking), conditional on not having already defaulted. 


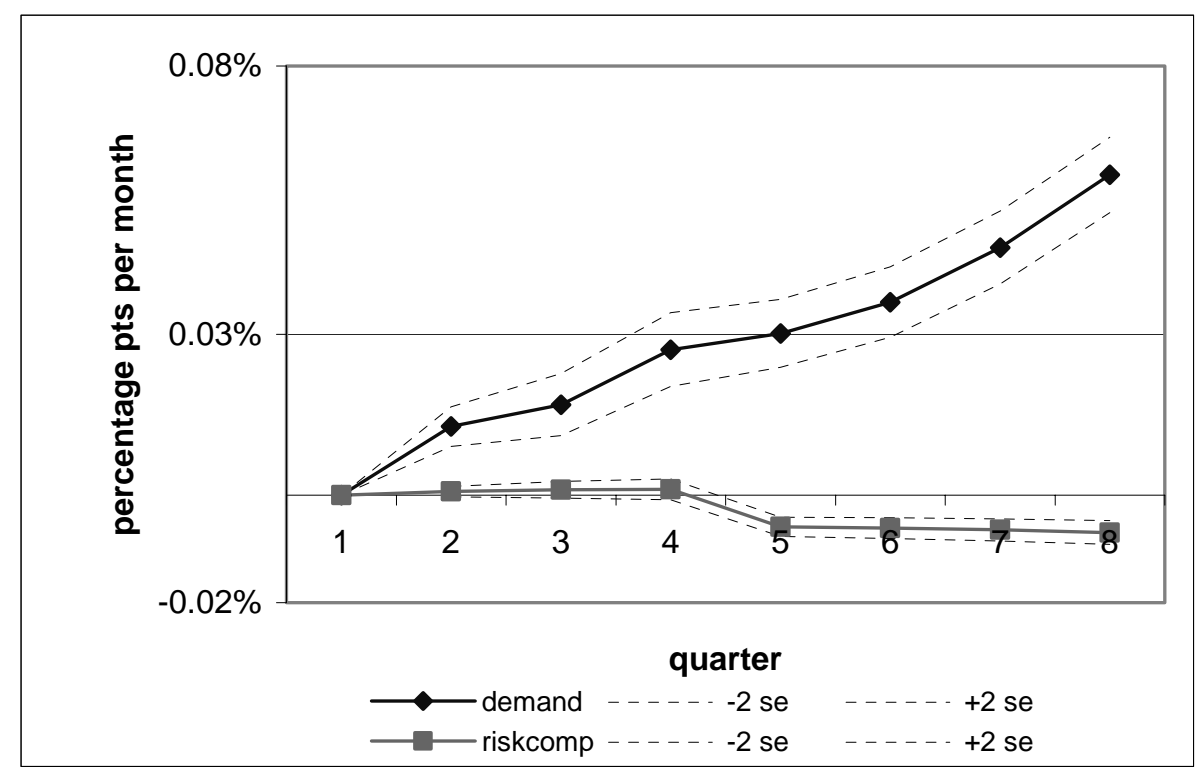

\section{Figure 3}

Marginal effects calculated from the baseline probit model of bankruptcy

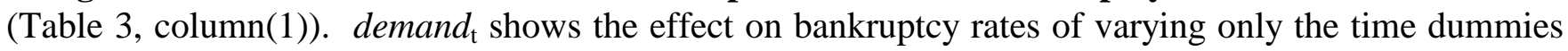
across quarters $t$, relative to the first quarter. riskcomp $p_{t}$ shows the effect of varying account age and the economic control variables across their cross-sectional averages in different quarters. See Eqs. (2) and (3). 


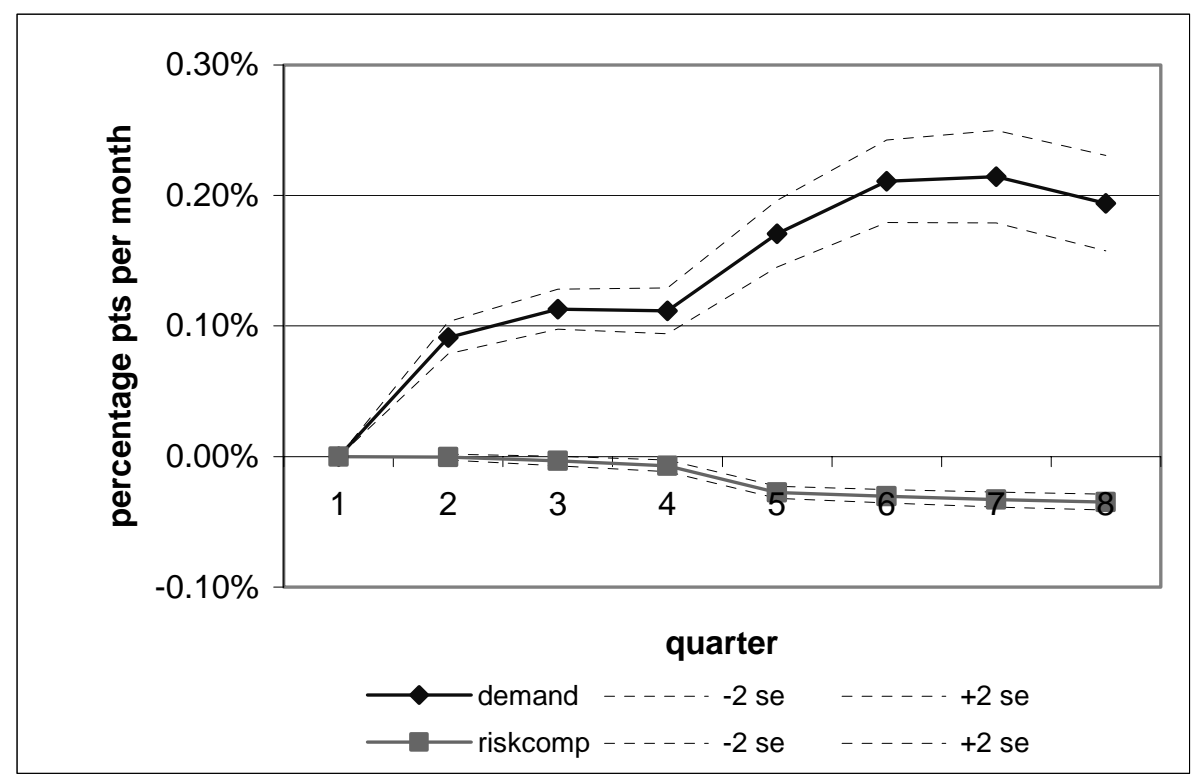

Figure 4

Marginal effects calculated from the baseline probit model of credit card delinquency

(Table 5, column(1)). demand d $_{\mathrm{t}}$ shows the effect on delinquency rates of varying only the time dummies across quarters $t$, relative to the first quarter. riskcomp $p_{t}$ shows the effect of varying account age and the economic control variables across their cross-sectional averages in different quarters. See Eqs. (2) and (3). 